Division of Geological \& Geophysical Surveys

RAW-DATA FILE 2005-5

\title{
MAJOR-OXIDE, MINOR-OXIDE, AND TRACE-ELEMENT GEOCHEMICAL DATA FROM ROCKS COLLECTED IN THE LIBERTY BELL AREA, FAIRBANKS A-4 QUADRANGLE, ALASKA, IN 2005
}

\author{
by \\ Jennifer E. Athey, Melanie B. Werdon, Rainer J. Newberry, David J. Szumigala, \\ Larry K. Freeman, and Richard R. Lessard
}

$\$ 3.00$

October 2005

THIS REPORT HAS NOT BEEN REVIEWED FOR TECHNICAL CONTENT OR FOR CONFORMITY TO THE

EDITORIAL STANDARDS OF DGGS

Released by

STATE OF ALASKA

DEPARTMENT OF NATURAL RESOURCES

Division of Geological \& Geophysical Surveys

3354 College Road

Fairbanks, Alaska 99709-3707 



\section{CONTENTS}

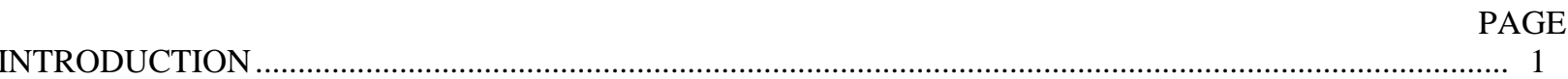

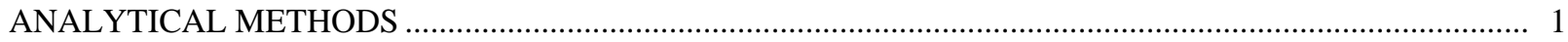

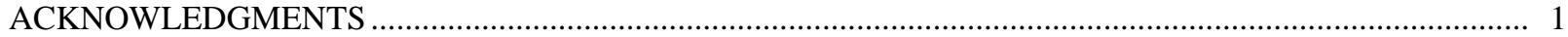

\section{TABLES}

TABLE 1.LOCATION AND DESCRIPTION OF ROCK SAMPLES COLLECTED FOR TRACEELEMENT GEOCHEMICAL ANALYSES IN THE LIBERTY BELL AREA, FAIRBANKS A-4 QUADRANGLE, ALASKA..

TABLE 2.CONCENTRATIONS OF TRACE ELEMENTS IN ROCK SAMPLES COLLECTED IN

THE LIBERTY BELL AREA, FAIRBANKS A-4 QUADRANGLE, ALASKA .12

TABLE 3.LOCATION AND DESCRIPTION OF ROCK SAMPLES COLLECTED FOR MAJOROXIDE, MINOR-OXIDE, AND TRACE-ELEMENT ANALYSIS IN THE LIBERTY

BELL AREA, FAIRBANKS A-4 QUADRANGLE, ALASKA 19

TABLE 4.CONCENTRATION OF MAJOR-OXIDES, MINOR-OXIDES, AND TRACEELEMENTS IN ROCK SAMPLES COLLECTED IN THE LIBERTY BELL AREA, FAIRBANKS A-4 QUADRANGLE, ALASKA.

TABLE 5.DETECTION LIMITS AND ANALYTICAL METHODS FOR TRACE-ELEMENT GEOCHEMICAL ANALYSES .28

TABLE 6.DETECTION LIMITS AND ANALYTICAL METHODS FOR MAJOR-OXIDE, MINOR-OXIDE, AND TRACE-ELEMENT ANALYSES

Note: This report (including all analytical data and tables) is available in digital format from the DGGS web site (http://wwwdggs.dnr.state.ak.us) at no charge. The digital data are available as PDF files and Excel spreadsheets. 



\title{
MAJOR-OXIDE, MINOR-OXIDE, AND TRACE-ELEMENT GEOCHEMICAL DATA FROM ROCKS COLLECTED IN THE LIBERTY BELL AREA, FAIRBANKS A-4 QUADRANGLE, ALASKA, IN 2005
}

\author{
by \\ Jennifer E. Athey, Melanie B. Werdon, Rainer J. Newberry, \\ David J. Szumigala, Larry K. Freeman, and Richard R. Lessard
}

\section{INTRODUCTION}

\begin{abstract}
Mineral-resources personnel from the Alaska Division of Geological \& Geophysical Surveys carried out a geological field survey, including mapping and sampling in the Liberty Bell area of the Fairbanks A-4 Quadrangle, Alaska, from July 11 through August 1, 2005. The fieldwork provides basic information critical to building an understanding of Alaska's geology and is part of an integrated program of airborne geophysical surveys followed by geological mapping. During 2005, 116 rock samples were collected for geochemical trace-element analysis, and 73 rock samples were collected for whole-rock (major- and minor-oxide, and petrogenetically important traceelements) analysis. Location coordinates were collected using hand-held GPS units (no differential correction was applied), with the exception of five core samples (05JEA1A, 05JEA2A, and 05JEA4A-05JEA6A) whose collar locations were determined in GIS from a georeferenced map and orthorectified aerial photographs. Coordinates are presented in latitude and longitude (based on the NAD 27 Alaska datum) and in UTM coordinates (based on the Clark 1866 spheroid, NAD 27 datum, UTM zone 6 projection). Additional details about the sampling program can be found in the metadata file associated with the digital version of this report. Sample numbers, location data, descriptions, and analytical results for each sample are tabulated in tables 1, 2, 3, and 4.
\end{abstract}

\section{ANALYTICAL METHODS}

All trace-element geochemical analyses (table 2) collected in 2005 were performed by ALS Chemex. Rock samples were crushed with a Terminator jaw crusher with chrome steel alloy plates so that at least 70 percent of the material passes through a $-10(2 \mathrm{~mm})$ mesh screen. Representative aliquots of 200 grams and 30 grams each were taken using a stainless steel riffle splitter. These samples were then pulverized in a chrome steel ring mill so that 85 percent of the sample passed through a -200 (75 micron) mesh screen. Most trace-element analyses were performed on the 200 gram split while gold analyses were performed on the 30 gram representative split.

Initially, all samples were assayed for gold by atomic absorption spectroscopy following a fire assay fusion (FAAAS). Samples containing greater than 1,000 ppb gold were also assayed by gravimetric finish following a fire assay fusion (FA-GRAV). Samples containing greater than $15 \mathrm{ppb}$ gold were assayed for mercury by atomic absorption spectroscopy (AAS) after aqua regia/cold vapor digestion. All other trace-element geochemical analyses were performed by inductively coupled plasma-atomic emission spectroscopy (ICP-AES) methods after four-acid, near-total digestion. This method of digestion is possibly incomplete for some elements and may result in lower analytical results for these elements. The elements that may be affected by incomplete digestion, analytical methods, and lower and upper detection limits are tabulated in table 5.

All whole-rock analyses (table 4) were performed by ALS Chemex. Major- and minor-element oxides were determined by X-ray fluorescence spectrometry following a lithium borate fusion (LBF-XRF), and trace elements were determined using X-ray fluorescence spectrometry on pressed pellets (PP-XRF). Analytical methods and detection limits are tabulated in table 6.

\section{ACKNOWLEDGMENTS}

This project is part of the Alaska Airborne Geophysical/Geological Mineral Inventory Program funded by the Alaska State Legislature and managed by State of Alaska, Department of Natural Resources, Division of Geological \& Geophysical Surveys. Partial funding for the geologic mapping and geochemical analyses was also provided through the U.S. Geological Survey STATEMAP Program under award number 05HQAG0025, and the State of Alaska Operating Budget General Fund. 


\begin{tabular}{|c|c|c|c|c|c|c|}
\hline Sample Number & Latitude & Longitude & UTM E & UTM N & Zone & Description \\
\hline 05JEA30C & 64.0293 & -148.9464 & 404906 & 7101536 & $06 \mathrm{~W}$ & Metarhyolite; altered paleozoic rock above dike with arsenopyrite and scorodite. \\
\hline 05JEA49A & 64.0732 & -148.8636 & 409092 & 7106300 & $06 \mathrm{~W}$ & $\begin{array}{l}\text { Phyllite; quartz veined and sericitized, with } 1 \text { percent arsenopyrite and scorodite } \\
\text { staining. Prospect pits. }\end{array}$ \\
\hline O5JEA121B & 64.0856 & -148.6123 & 421384 & 7107352 & $06 \mathrm{~W}$ & Quartz vein; with green mineral (epidote?) and weathered pyrite. \\
\hline 05JEA249A & 64.0748 & -148.7443 & 414916 & 7106322 & $06 \mathrm{~W}$ & $\begin{array}{l}\text { Conglomerate; bedded and lithified Tertiary rock with clasts of schist, white quartz, } \\
\text { and black quartzite }(\leq 2 \text { inches in diameter), and quartz grains }(1-2 \mathrm{~mm}) \text { cemented } \\
\text { by a sericite(?) }+ \text { silica(?) matrix. }\end{array}$ \\
\hline 05JEA254C & 64.0945 & -148.8225 & 411164 & 7108620 & $06 \mathrm{~W}$ & Phyllite; with quartz veins; strong iron oxide and trace green scorodite(?) staining. \\
\hline 05JEA256C & 64.0960 & -148.8186 & 411357 & 7108776 & $06 \mathrm{~W}$ & $\begin{array}{l}\text { Quartz vein; } \sim 4 \text { inches thick, parallel to foliation, weakly mineralized, with minor light } \\
\text { green scorodite(?) staining and sericite alteration. }\end{array}$ \\
\hline 05JEA259A & 64.0984 & -148.8211 & 411247 & 7109052 & 06W & Quartz vein; fractured with iron oxide and possible arsenopyrite. \\
\hline 05LF39B & 64.0546 & -148.7437 & 414881 & 7104070 & $06 \mathrm{~W}$ & $\begin{array}{l}\text { Quartz stockwork; white, milky quartz in veinlets }(\leq 3 \mathrm{~cm} \text { wide), cut by drusy } \\
\text { gossanous gashes fractures, and } 1 \text { percent limonite in semi-schist (metagranite } \\
\text { host). }\end{array}$ \\
\hline 05LF40B & 64.0550 & -148.7429 & 414925 & 7104112 & 06W & $\begin{array}{l}\text { Fault breccia; limonite cemented, with } 10 \text { percent quartz veins. Breccia zone is in } \\
\text { conjugate fractures along larger fault zone. }\end{array}$ \\
\hline 05LF42B & 64.0568 & -148.7379 & 415175 & 7104308 & $06 \mathrm{~W}$ & $\begin{array}{l}\text { Semi-schist; green, rusty, with } 25 \text { percent pale green quartz eyes, and very-fine- to } \\
\text { coarse-grained pyrite. }\end{array}$ \\
\hline 05LF52A & 64.0708 & -148.6479 & 419603 & 7105746 & $06 \mathrm{~W}$ & $\begin{array}{l}\text { Rhyolite-granite; } 3-10 \mathrm{~cm} \text { pieces in regolith, porphyritic, with } 10 \text { percent euhedral } \\
\text { quartz (1-3 mm), 5-10 percent clay altered relict feldspar, in a waxy-clay altered } \\
\text { aphanitic matrix. }\end{array}$ \\
\hline 05LF53B & 64.0689 & -148.6453 & 419726 & 7105536 & $06 \mathrm{~W}$ & $\begin{array}{l}\text { Quartz-tourmaline vein; } 10 \text { percent of regolith, } 2-10 \mathrm{~cm} \text { pieces in } 10 \mathrm{~m} \text {-wide zone, } \\
\text { contains 5-40 percent red-brown/limonite coated boxwork, with no relict sulfides. }\end{array}$ \\
\hline 05LF57C & 64.0655 & -148.6242 & 420747 & 7105122 & $06 \mathrm{~W}$ & $\begin{array}{l}\text { Phyllite; strongly sericite altered, with } 10 \text { percent quartz eyes }(1 \mathrm{~mm}) \text { in a light green, } \\
\text { very-fine-grained, sugary matrix. } 5 \text { percent disseminated pyrite. }\end{array}$ \\
\hline 05LF59B & 64.0678 & \begin{tabular}{|l|}
-148.6152 \\
\end{tabular} & \begin{tabular}{|l|l|}
421190 \\
\end{tabular} & 7105370 & $06 \mathrm{~W}$ & Quartz-chlorite vein; white quartz with black chlorite selvages. \\
\hline 05LF61B & 64.0707 & -148.6042 & 421738 & 7105685 & $06 \mathrm{~W}$ & $\begin{array}{l}\text { Granite; porphyritic, strongly altered, sericitized, relict fine grain textured quartz, and } \\
\text { fractures with veinlets of green-yellow and gray boxwork quartz. }\end{array}$ \\
\hline 05LF75B & 64.0785 & -148.5809 & 422893 & 7106521 & 06W & $\begin{array}{l}\text { Granite dike; } 20-\mathrm{m} \text {-wide, gray, porphyritic, very-fine-grained, with } 10 \text { percent } \\
\text { euhedral quartz }(2 \mathrm{~mm}) \text { and black fine grained biotite, in a very-fine-grained, sugary } \\
\text { groundmass. Strong sericite and clay alteration, with } 1 \text { percent disseminated gray } \\
\text { unknown mineral replaced mafic mineral. }\end{array}$ \\
\hline
\end{tabular}




\begin{tabular}{|c|c|c|c|c|c|c|}
\hline Sample Number & Latitude & Longitude & UTME & UTM N & Zone & Description \\
\hline 05LF75C & 64.0785 & -148.5809 & 422893 & 7106521 & 06W & $\begin{array}{l}\text { Granite dike; gray, porphyritic, very-fine-grained, with } 10 \text { percent euhedral quartz (2 } \\
\mathrm{mm} \text { ) and black fine-grained biotite, in a very-fine-grained, sugary groundmass. } \\
\text { Strong sericite and clay alteration, with } 1 \text { percent disseminated gray unknown } \\
\text { mineral after mafic mineral, and } 2-3 \mathrm{~mm} \text { fracture fillings of quartz-tourmaline } \\
\text { containing stibnite-like mineral in yellow boxwork. }\end{array}$ \\
\hline 05LF75E & 64.0785 & -148.5809 & 422893 & 7106521 & 06W & $\begin{array}{l}\text { Quartz-tourmaline vein in schist; } 1 \text { inch wide, brecciated quartz infilled with } \\
\text { tourmaline, oxidized gray sulfide, and yellow oxide possible stibiconite. }\end{array}$ \\
\hline 05LF77A & 64.0792 & -148.5820 & 422844 & 7106607 & 06W & Quartz vein; $5 \mathrm{~cm}$ thick, drusy quartz, with 30 percent arsenopyrite infill. \\
\hline 05LF78A & 64.0798 & -148.5817 & 422860 & 7106673 & 06W & $\begin{array}{l}\text { Quartz vein; } 2-5 \mathrm{~cm} \text { wide, brecciated, with } 75 \text { percent gray-white quartz, 5-20 } \\
\text { percent arsenopyrite infill, } 5 \text { percent green tourmaline, } 5 \text { percent boxwork, and 0-20 } \\
\text { percent green-blue cryptocrystalline infill - unknown. }\end{array}$ \\
\hline 05LF79B & 64.0832 & -148.5802 & 422944 & 7107050 & 06W & $\begin{array}{l}\text { Fault breccia; bleached, with quartz-arsenopyrite-unknown-gray mineral vein, 0.6-m- } \\
\text { wide chip sample. }\end{array}$ \\
\hline 05LF92A & 64.0633 & -148.6258 & 420661 & 7104888 & 06W & $\begin{array}{l}\text { Andesite; tan, porphyritic, } 95 \text { percent silicified, with } 5 \text { percent rectangular and } \\
\text { octahedral orthopyroxene pits, altered to white clay, limonite pseudomorphs of pyrite } \\
\text { trace scorodite. }\end{array}$ \\
\hline 05LF93B & 64.0621 & -148.6262 & 420641 & 7104754 & $06 \mathrm{~W}$ & $\begin{array}{l}\text { Quartz-tourmaline vein; } 3-\mathrm{cm} \text {-wide, banded, with green-black acicular tourmaline in } \\
\text { gray quartz, and up to } 2 \text { percent limonite boxwork. }\end{array}$ \\
\hline 05LF96A & 64.0573 & -148.6336 & 420264 & 7104227 & 06W & Breccia; clasts of sericite-altered, fine-grained, intrusive rock, with Fe-oxide cement. \\
\hline 05LF99A & 64.0514 & -148.6369 & 420086 & 7103570 & 06W & $\begin{array}{l}\text { Schist; (metagranite), fine-grained, with } 20 \text { percent quartz }(1 \mathrm{~mm}), 60 \text { percent } \\
\text { feldspar, } 20 \text { percent greenish sericite, and } 1 \mathrm{~mm} \text { green tourmaline } \pm \text { sericite veinlets } \\
\text { every } 1-2 \mathrm{~cm} \text {. }\end{array}$ \\
\hline 05LF113A & 64.0341 & -148.6629 & 418765 & 7101675 & 06W & $\begin{array}{l}\text { Schist; (metarhyolite), light green, strongly bleached, foliated, porphyritic, with } \\
\text { sericite, feldspar, quartz, and } 1 \text { percent quartz vein with limonite pseudomorphs of } \\
\text { pyrite in fractures. }\end{array}$ \\
\hline 05LF140B & 64.0581 & -148.5052 & 426531 & 7104159 & 06W & Quartz vein/fracture zone; with limonite, gossan, boxwork, and yellow powdery oxide \\
\hline 05LF141A & 64.0660 & -148.5014 & 426738 & 7105041 & 06W & $\begin{array}{l}\text { Quartz vein; 4-m-thick, fine-grained quartz, with disseminated pyrite, arsenopyrite, } \\
\text { and locally brecciated with infill of stibnite. }\end{array}$ \\
\hline 05LF141B & 64.0660 & -148.5014 & 426738 & 7105041 & 06W & $\begin{array}{l}\text { Quartz breccia vein; angular blocks of quartz in matrix and with fractures filled with } \\
\text { massive stibnite, with possible arsenopyrite and galena. Grab sample of } 0.4 \text {-m-thick } \\
\text { zone in larger quartz vein. }\end{array}$ \\
\hline
\end{tabular}




\begin{tabular}{|c|c|c|c|c|c|c|}
\hline Sample Number & Latitude & Longitude & UTM E & UTM N & Zone & Description \\
\hline 05LF160B & 64.1031 & -148.5276 & 425558 & 7109202 & $06 \mathrm{~W}$ & $\begin{array}{l}\text { Schist; (metagranite porphyry), megablastic, foliated, strongly bleached and oxidized } \\
\text { to kaolin(?) and quartz; locally relic green sericite-quartz alteration with disseminated } \\
\text { tourmaline, arsenopyrite, and pyrite. }\end{array}$ \\
\hline 05LF171B & 64.0879 & -148.7929 & 412588 & 7107839 & 06W & $\begin{array}{l}\text { Vein; 2-cm-thick limonite gossan in anastomosing fractures, cross-cut foliation, with } \\
\text { yellow-green oxide. }\end{array}$ \\
\hline 05LF180A & 64.0762 & -148.7658 & 413870 & 7106503 & 06W & \begin{tabular}{|l} 
Quartz breccia; forming prominent rib, silica flooded, white altered schist \\
(metarhyolite) clasts, with very fine chalcedonic quartz cement, local tourmaline.
\end{tabular} \\
\hline 05LF210A & 64.0565 & -148.8072 & 411792 & 7104365 & 06W & $\begin{array}{l}\text { Semi-schist; (metagranite), hornfelsed, with quartz eyes, and up to } 1 \text { percent } \\
\text { disseminated pyrite. }\end{array}$ \\
\hline 05LF211B & 64.0398 & -148.5324 & 425155 & 7102154 & $06 \mathrm{~W}$ & $\begin{array}{l}\text { Schist; (metagranite), foliated, medium-grained, } 10 \text { percent quartz eyes, } 40 \text { percent } \\
\text { feldspar eyes }(1-5 \mathrm{~mm}), 40 \text { percent quartz-feldspar bands }(<1 \mathrm{~mm}) \text {. Bleached, } \\
\text { sericite-altered, and strong yellow stain with up to } 2 \text { percent disseminated pyrite. }\end{array}$ \\
\hline 05LF226A & 64.0590 & -148.7310 & 415515 & 7104541 & 06W & $\begin{array}{l}\text { Schist; green with 5-15 percent quartz }(1 \mathrm{~mm}), 20-40 \text { percent feldspar }(1 \mathrm{~mm}) \\
\text { altered to sericite, and fractures with limonite staining after pyrite. }\end{array}$ \\
\hline 05LF228A & 64.0556 & -148.8664 & 408900 & 7104351 & 06W & $\begin{array}{l}\text { Vein; 3- to 5-cm-wide, in white sericite altered felsic rock, with quartz, tourmaline, } \\
\text { and arsenopyrite from push-pile in "northwest copper zone," Liberty Bell property. }\end{array}$ \\
\hline 05LF230A & 64.0576 & -148.8429 & 410049 & 7104535 & $06 \mathrm{~W}$ & $\begin{array}{l}\text { Skarn; (skarn), foliated, with acicular actinolite, cut by quartz-sericite veins, } 1 \text { percent } \\
\text { chalcopyrite, } 2 \text { percent pyrrhotite, and trace arsenopyrite. Industry map unit } \\
\text { "Mesozoic meta-gabbro." }\end{array}$ \\
\hline 05LF231A & 64.0585 & -148.8577 & 409330 & 7104660 & $06 \mathrm{~W}$ & $\begin{array}{l}\text { Skarn; (skarn), medium- to coarse-grained, random-oriented actinolite with } \\
\text { interstitial plagioclase, 1-4 percent pyrrhotite, 2-3 percent chalcopyrite, } 1 \text { percent } \\
\text { arsenopyrite. Industry map unit "Mesozoic meta-gabbro." }\end{array}$ \\
\hline 05LF231B & 64.0585 & -148.8577 & 409330 & 7104660 & $06 \mathrm{~W}$ & $\begin{array}{l}\text { Silicified rock; (skarn), gray to light green, dense, aphanitic, with } 2 \text { percent } \\
\text { arsenopyrite (1-2 mm), and very-fine-grained euhedral pyrite. }\end{array}$ \\
\hline 05MBW36B & 64.0495 & -148.9184 & 406338 & 7103743 & 06W & $\begin{array}{l}\text { Hornfels; bright orange weathering, mottled and spotted adjacent to a sericitized, } \\
\text { granite porphyry dike that is cut by brown tourmaline veinlets that strike } 223 \text { degrees } \\
\text { (azimuth) and dip } 63 \text { degrees. }\end{array}$ \\
\hline 05MBW37A & 64.0495 & -148.9238 & 406078 & 7103750 & 06W & $\begin{array}{l}\text { Rhyolite dike; white to tan to rusty orange weathering, with quartz phenocrysts. Cut } \\
\text { by stockwork quartz and brown tourmaline, or quartz only, or tourmaline only veins. } \\
\text { One vein strikes } 295 \text { degrees (azimuth) and dips } 63 \text { degrees. }\end{array}$ \\
\hline 05MBW40A & 64.0485 & -148.9247 & 406029 & 7103645 & $06 \mathrm{~W}$ & $\begin{array}{l}\text { Gossan-breccia; angular fragments of pinkish orange and gray weathering hornfels } \\
\text { up to } 1 \text { inch across, cemented with medium to dark brown goethite or limonite. }\end{array}$ \\
\hline 05MBW47A & 64.0495 & -148.9282 & 405863 & 7103755 & 06W & $\begin{array}{l}\text { Hornfels; composed of white, granular quartz grains }(\leq 1 \mathrm{~mm}) \text {. Tourmaline usually } \\
\text { occurs as veins and occasionally massive replacements(?). Local faint red/yellow } \\
\text { weathering, suggesting possible scorodite or kermesite(?). Small prospecting trench } \\
\text { at this site. }\end{array}$ \\
\hline
\end{tabular}




\begin{tabular}{|c|c|c|c|c|c|c|}
\hline \multicolumn{7}{|c|}{ Table 1. (continued) } \\
\hline Sample Number & Latitude & Longitude & UTM E & UTM N & Zone & Description \\
\hline 05MBW50A & 64.0475 & -148.9273 & 405897 & 7103538 & 06W & $\begin{array}{l}\text { Intermediate composition dike; (granodiorite), grayish-green, brown weathering, } \\
\text { porphyritic, with biotite and quartz phenocryst. Contains disseminated pyrite and } \\
\text { arsenopyrite. }\end{array}$ \\
\hline 05MBW54B & 64.0495 & -148.9297 & 405786 & 7103756 & $06 \mathrm{~W}$ & $\begin{array}{l}\text { Breccia zone; brecciated, hornfelsed metasedimentary rock adjacent to a quartz- } \\
\text { phyric, sericite-altered felsic dike. Geochemical sample taken from both the meta- } \\
\text { sedimentary rock breccia and a shear zone within the dike that contains brown } \\
\text { tourmaline and quartz. Breccia zone along dike-wall rock contact strikes } 183 \\
\text { degrees (azimuth) and dips } 50 \text { degrees. Shear zone containing tourmaline and } \\
\text { fractured quartz strikes } 343 \text { degrees (azimuth) and dips } 75 \text { degrees. }\end{array}$ \\
\hline 05MBW67A & 64.0458 & -148.9400 & 405271 & 7103363 & 06W & $\begin{array}{l}\text { Hornfels; white, Fe-oxide coated, sugary, finely granular. Cut by up to } 1.5-\mathrm{cm} \text {-wide } \\
\text { veins of brown, fine-grained, felted tourmaline masses, containing up to } 5 \text { percent } \\
\text { disseminated pyrite. Veins also contain euhedral quartz crystals formed in open vugs } \\
\text { up to } 1.4 \mathrm{~cm} \text { long. Vein set strikes } 302 \text { degrees (azimuth) and dips } 74 \text { degrees. }\end{array}$ \\
\hline 05MBW105C & 64.0763 & -148.8832 & 408148 & 7106675 & 06W & $\begin{array}{l}\text { Granite dike; white, equigranular, fine grained, with no visible mafics, cut by } \\
\text { stockwork quartz } \pm \text { Fe-oxide bearing veins up to } 1 \mathrm{~cm} \text { wide. }\end{array}$ \\
\hline 05MBW106A & 64.0760 & -148.8831 & 408151 & 7106648 & 06W & $\begin{array}{l}\text { Granite dike; white, equigranular, fine grained, with no visible mafics, weathers white } \\
\text { except where stained red, orange, yellow, and brown near quartz and Fe-oxide } \\
\text { stockwork veins up to } 3 \mathrm{~cm} \text { wide. }\end{array}$ \\
\hline 05MBW113A & 64.0822 & -148.8704 & 408789 & 7107320 & 06W & Quartz; white, angular fragments in a > 100-foot-wide fault(?) zone. \\
\hline 05MBW133A & 64.0726 & -148.9201 & 406335 & 7106324 & 06W & $\begin{array}{l}\text { Phyllite; pale gray weathering, finely color laminated, foliated, fissile, aphanitic, lightly } \\
\text { Fe-oxide coated, composed of quartz and white mica. Locally quartz veined, } \\
\text { brecciated, and silica flooded. Contains disseminated Fe-oxide (former pyrite } \\
\text { cubes). Breccia zone strikes } 293 \text { degrees (azimuth) and dips } 62 \text { degrees. }\end{array}$ \\
\hline 05MBW163A & 64.0600 & -148.5651 & 423615 & 7104440 & $06 \mathrm{~W}$ & Quartz-feldspar vein; yellow coating might be stibiconite(?). \\
\hline 05MBW166B & 64.0595 & -148.5609 & 423817 & 7104377 & $06 \mathrm{~W}$ & Vein; white and massive quartz with limonite and local vugs. \\
\hline 05MBW167A & 64.0590 & -148.5598 & 423869 & 7104320 & 06W & $\begin{array}{l}\text { Vein; quartz and green white mica(?) } \pm \text { trace limonite (after sulfides?) plus yellow } \\
\text { staining on surfaces (potentially cerusite?). }\end{array}$ \\
\hline 05MBW169A & 64.0574 & -148.5562 & 424041 & 7104138 & 06W & $\begin{array}{l}\text { Quartz vein; white, vuggy, with red and yellow Fe-oxide. Contains sericitized wall } \\
\text { rock inclusions and crystalline tan feldspar. Yellow color may be stibiconite(?). }\end{array}$ \\
\hline 05MBW174A & 64.0571 & -148.5496 & 424362 & 7104098 & 06W & $\begin{array}{l}\text { Quartz vein; small prospecting pit containing light yellow-stained quartz vein } \\
\text { material, dark-brown Fe-oxide and quartz-crystal breccias, and intergrown quartz } \\
\text { and Fe-oxide. Scattered vein material composed of massive, dark-gray stibnite, } \\
\text { and cubic pyrite. Mineralized fault zone trends approximately } 155 \text { degrees (azimuth). }\end{array}$ \\
\hline
\end{tabular}




\begin{tabular}{|c|c|c|c|c|c|c|}
\hline $\begin{array}{l}\text { Table 1. (continu } \\
\text { Sample Number }\end{array}$ & Latitude & ongitude & UTME & UTM N & Zone & Description \\
\hline 05MBW209B & 64.0675 & -148.5387 & 424923 & 7105243 & 06W & $\begin{array}{l}\text { Rhyolite porphyry dikes; } 1 \text { inch by } 1 \text { foot, with } 15 \text { percent quartz and } 20 \text { percent } \\
\text { feldspar phenocrysts }(\leq 1.5 \mathrm{~mm}) \text {. Cut by stibiconite- and Fe-oxide-filled fractures } \\
\text { with or without crystalline quartz that has grown outward from the wall rock. }\end{array}$ \\
\hline 05MBW223A & 64.0521 & -148.5784 & 422945 & 7103577 & 06W & $\begin{array}{l}\text { Breccia; black, aphanitic to finely granular, Fe-oxide coated, with disseminated } \\
\text { pyrite (up to } 0.5 \mathrm{~mm} \text { in diameter). Locally cut by Fe-oxide filled, } 1-\mathrm{cm} \text {-wide } \\
\text { fractures. }\end{array}$ \\
\hline 05MBW224A & 64.0494 & -148.5785 & 422929 & 7103278 & 06W & $\begin{array}{l}\text { Meta-ash(?); gray colored, yellow-, orange-, and gray-weathering, foliated, aphanitic } \\
\text { to very finely granular, finely color laminated, with Fe-oxide and possibly } \\
\text { stibiconite(?) coatings. Contains disseminated, empty vugs (up to } 0.2 \mathrm{~mm} \text { in } \\
\text { diameter) that may have contained sulfides. }\end{array}$ \\
\hline 05MBW225A & 64.0481 & -148.5770 & 423000 & 7103136 & 06W & $\begin{array}{l}\text { Quartz vein; mottled gray- and white-colored, yellow and orange-brown weathering, } \\
\text { Fe-oxide and possibly scorodite(?) coated, contains irregular, tiny (0.5- to 1-mm } \\
\text { diameter) vugs } \pm \text { filled with Fe-oxide. }\end{array}$ \\
\hline 05MBW257A & 64.0316 & -148.6617 & 418817 & 7101397 & 06W & Brecciated carbonaceous phyllite; bright orange and brown, gossanous. \\
\hline 05MBW290A & 64.0561 & -148.7290 & 415606 & 7104216 & 06W & $\begin{array}{l}\text { Phyllite; contains vuggy gossanous areas and is cut by foliation-crossing quartz } \\
\text { veins. Heavily Fe-oxide coated, with yellow and greenish-yellow oxide coatings } \\
\text { (scorodite?). }\end{array}$ \\
\hline 05MBW292A & 64.0564 & -148.7276 & 415672 & 7104245 & 06W & $\begin{array}{l}\text { Fault gouge; } 1 \text { - to } 2 \text {-inch-wide fault zone that widens out to approximately 1-foot } \\
\text { wide cutting foliation in phyllite. Fault is filled with brecciated, angular wall rock } \\
\text { fragments, rock flour, and quartz veins with finely disseminated arsenopyrite. Fault } \\
\text { strikes } 309 \text { degrees (azimuth) and dips } 30 \text { degrees. }\end{array}$ \\
\hline 05MBW293A & 64.0571 & -148.7272 & 415695 & 7104319 & 06W & $\begin{array}{l}\text { Phyllite; Fe-oxide coated, highly quartz-veined, quartz- and feldspar-phyric } \\
\text { metarhyolite with disseminated, fine grained pyrite. }\end{array}$ \\
\hline 05MBW296A & 64.0606 & -148.7236 & 415883 & 7104714 & 06W & $\begin{array}{l}\text { Phyllite; light greenish gray, massive, foliated, with relict quartz and feldspar } \\
\text { phenocrysts, and white mica. Highly Fe-oxide coated, with up to } 20 \text { percent } \\
\text { disseminated pyrite. }\end{array}$ \\
\hline 05MBW296B & 64.0606 & -148.7236 & 415883 & 7104714 & 06W & $\begin{array}{l}\text { Quartz vein; from shear zone up to } 3 \text { inches wide. Sample contains light gray to } \\
\text { clear quartz with disseminated crystals }(\leq 3 \mathrm{~mm} \text { ) of arsenopyrite up to } 40 \text { percent of } \\
\text { vein but generally }<20 \text { percent. Shear zone strikes } 258 \text { degrees (azimuth) and dips } \\
38 \text { degrees. }\end{array}$ \\
\hline 05MBW297A & 64.0640 & -148.7255 & 415801 & 7105089 & 06W & $\begin{array}{l}\text { Phyllite; Fe-oxide- and yellow-oxide-stained, contains up to } 10 \text { percent disseminated } \\
\text { pyrite cubes ( } \leq 1.5 \mathrm{~mm} \text { in diameter) in wall rock, and is cut by veins of quartz, Fe- } \\
\text { oxide, and trace scorodite. }\end{array}$ \\
\hline 05MBW & 64.0643 & -148.7233 & 415908 & 7105119 & 06W & $\begin{array}{l}\text { Metarhyolite; brecciated, sheared, and } \pm \text { quartz-veined. Quartz veins } \pm \\
\text { disseminated vugs, } \pm \text { coated with scorodite. }\end{array}$ \\
\hline
\end{tabular}




\begin{tabular}{|c|c|c|c|c|c|c|}
\hline Sample Number & Latitude & Longitude & UTM E & UTM N & Zone & Description \\
\hline 05MBW300A & 64.0648 & -148.7224 & 415955 & 7105175 & 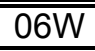 & Fault gouge; in metarhyolite with heavily Fe-oxide stained rock flour. \\
\hline 05MBW301A & 64.0655 & -148.7194 & 416101 & 7105248 & 06W & $\begin{array}{l}\text { Skarn(?) or hornfels; green, red, and gray, rusty weathering, hard, massive, finely } \\
\text { granular, with up to } 10 \text { percent disseminated pyrrhotite. }\end{array}$ \\
\hline 05MBW303A & 64.0671 & -148.7230 & 415930 & 7105437 & $06 \mathrm{~W}$ & $\begin{array}{l}\text { Shear zone; varies from 1- to } 3 \text {-feet wide, with peripheral quartz + iron oxide veins } \\
\text { extending off of the main shear zone. Heavily Fe-oxide- and yellow-stained veins } \\
\text { contain quartz, pyrite, and arsenopyrite, with dark brownish-green tourmaline sprays, } \\
\text { chlorite(?), secondary Fe-oxide, and scorodite. Shear zones strike } 310 \text { degrees } \\
\text { (azimuth) and dip } 60 \text { degrees. }\end{array}$ \\
\hline 05MBW305A & 64.0682 & -148.7289 & 415644 & 7105559 & 06W & $\begin{array}{l}\text { Silicified fault zone; in metarhyolite cut by micro-fractures of quartz containing } 5 \\
\text { percent fine grained disseminated pyrite cubes }(<0.5 \mathrm{~mm} \text { in diameter). }\end{array}$ \\
\hline 05MBW320C & 64.0629 & -148.9218 & 406219 & 7105241 & 06W & Hornfels; quartz and Fe-oxide veins with dark green tourmaline crystals $(\leq 2 \mathrm{~mm})$. \\
\hline 05MBW322A & 64.0643 & -148.9258 & 406030 & 7105401 & 06W & $\begin{array}{l}\text { Hornfelsed(?) meta-ash or meta-argillite; variably Fe-oxide stained, cut by } 6 \text {-inch- } \\
\text { wide zone of quartz, fine-grained brown tourmaline, and limonite veins ( } 1 \mathrm{~mm} \text { to } 1 \\
\mathrm{~cm} \text { wide). Veins occur in the center of a 2-foot-wide Fe-oxide stained zone. }\end{array}$ \\
\hline 05MBW325B & 64.0647 & -148.9306 & 405798 & 7105460 & 06W & $\begin{array}{l}\text { Fault breccia; } 1 \text { - to } 2-\mathrm{cm} \text { diameter, angular fragments of carbonaceous phyllite } \\
\text { cemented by Fe-oxide. }\end{array}$ \\
\hline 05MBW345A & 64.0608 & -148.9333 & 405651 & 7105027 & 06W & $\begin{array}{l}\text { Phyllite; white, granular silica-rich and carbon-rich layers, bright yellow and Fe-oxide } \\
\text { stained. }\end{array}$ \\
\hline 05MBW355A & 64.0564 & -148.9463 & 405000 & 7104550 & 06W & $\begin{array}{l}\text { Hornfelsed carbonaceous phyllite; } \\
\text { veins up to } 5 \text { inches thick. }\end{array}$ \\
\hline 05MBW363A & 64.0566 & -148.9543 & 404610 & 7104593 & 06W & $\begin{array}{l}\text { Quartz vein; Loose rubble of hornfelsed, carbonaceous metasedimentary rocks that } \\
\text { have been intruded and hornfelsed by a fine-grained, equigranular, granite dike, } \\
\text { which is cut by quartz veins. Sampled heavily Fe-oxide-coated, gray, massive, } \\
\text { granular quartz vein material that is intergrown with very fine-grained arsenopyrite } \\
\text { and stibnite. Locally stibnite crystals are up to } 2 \text { inches long. }\end{array}$ \\
\hline 05MBW365A & 64.0559 & -148.9564 & 404508 & 7104519 & $06 \mathrm{~W}$ & Fault breccia; limonitic gossan. \\
\hline 05MBW374A & 64.0528 & -148.9624 & 404205 & 7104179 & 06W & $\begin{array}{l}\text { Hornfelsed meta-argillite; white, foliated, very finely granular, cut by veins (up to } 1 \\
\text { inch wide) and veinlets containing various combinations of white crystalline quartz, } \\
\text { sprays and mats of very tiny, acicular, brown- to forest green-colored tourmaline } \\
\text { crystals, and disseminated Fe-oxides (after pyrite(?) cubes). }\end{array}$ \\
\hline 05MBW380A & 64.0557 & -148.9762 & 403542 & 710 & 06W & $\begin{array}{l}\text { Breccia; located in a }>250 \text {-foot-wide, Fe-stained, east-west-trending fault zone. Fe- } \\
\text { oxide cemented breccia with angular clasts of quartz-veined carbonaceous phyllite } \\
\text { up to } 2 \text { inches in diameter. }\end{array}$ \\
\hline
\end{tabular}




\begin{tabular}{|c|c|c|c|c|c|c|}
\hline Sample Number & Latitude & Longitude & UTM E & UTM N & Zone & Description \\
\hline 05MBW385A & 64.0506 & -148.9924 & 402733 & 7103981 & $06 \mathrm{~W}$ & $\begin{array}{l}\text { Quartz vein and breccia; hornfelsed phyllite cut by veins of dark-brown, very-fine- } \\
\text { grained mats of tourmaline within fractures up to } 5 \mathrm{~mm} \text { wide. Some tourmaline } \\
\text { veins are accompanied by Fe-oxide, and other quartz veins are up to } 1 \mathrm{~cm} \text { wide. } \\
\text { Phyllite is locally brecciated and cemented with Fe-oxide. }\end{array}$ \\
\hline 05MBW386A & 64.0506 & -148.9950 & 402605 & 7103986 & $06 \mathrm{~W}$ & $\begin{array}{l}\text { Phyllite; bright orange-brown weathering, heavily Fe-oxide coated, white, foliated, } \\
\text { hornfelsed. Cut by micro-fractures and veins variably filled with quartz, tourmaline, } \\
\text { and Fe-oxide (partially after pyrite(?) cubes). }\end{array}$ \\
\hline 05MBW395B & 64.0670 & -148.9719 & 403788 & 7105770 & $06 \mathrm{~W}$ & Gossan: quartz and Fe-oxide. \\
\hline 05MBW407A & 64.0532 & -148.7248 & 415799 & 7103886 & $06 \mathrm{~W}$ & $\begin{array}{l}\text { Quartz vein; abundant Fe-oxide coating, yellow oxides (scorodite), and local } \leq 1 \\
\text { percent pyrite in hornfelsed phyllite. }\end{array}$ \\
\hline 05MBW412A & 64.0470 & -148.7238 & 415831 & 7103199 & $06 \mathrm{~W}$ & Quartz vein: phyllite that is highly fractured and quartz veined. \\
\hline 05MBW417A & 64.0632 & -148.9777 & 403495 & 7105359 & $06 \mathrm{~W}$ & Dike; cut by crystalline, vuggy, quartz and limonite veins. \\
\hline 05MBW426A & 64.0670 & -148.9718 & 403794 & 7105774 & 06W & Gossan; in red Fe-oxide-stained carbonaceous phyllite. \\
\hline 05RN348A & 64.0170 & -148.5353 & 424952 & 7099621 & 06W & Phyllite; metarhyolite(?), cut by quartz-sulfide veins. \\
\hline 05RN424A & 64.0227 & -148.5371 & 424880 & 7100252 & $06 \mathrm{~W}$ & $\begin{array}{l}\text { Meta-granite; foliated, medium grained, quartz and feldspar }(2-4 \mathrm{~mm}) \text { with } 0.5 \text { to } 1 \\
\mathrm{~cm} \text { thick folded veins, } 20-60 \text { percent pyrite cubes with remainder quartz. }\end{array}$ \\
\hline 05RN426C & 64.0243 & -148.5379 & 424848 & 7100437 & $06 \mathrm{~W}$ & $\begin{array}{l}\text { Schist; sericitized feldspar and quartz, with abundant veins, } 50-70 \text { percent pyrite and } \\
\text { remainder quartz. }\end{array}$ \\
\hline 05Z51B & 64.0913 & -148.7301 & 415660 & 7108139 & $06 \mathrm{~W}$ & $\begin{array}{l}\text { Quartz-tourmaline-chlorite veins; white, black, and orange, Fe-oxide stained, vuggy, } \\
\text { with euhedral quartz crystals, and dark green chlorite mats on some vein selvages. } \\
\text { Moderate limonite. }\end{array}$ \\
\hline 05Z55B & 64.0846 & -148.7291 & 415684 & 7107386 & $06 \mathrm{~W}$ & $\begin{array}{l}\text { Quartz vein; yellowish-white, with chlorite clots, and open spaces with weak to } \\
\text { moderate limonite staining, and some patches of brick red Fe-oxide. }\end{array}$ \\
\hline 05Z56B & 64.0883 & -148.7207 & 416105 & 7107794 & $06 \mathrm{~W}$ & $\begin{array}{l}\text { Quartz-Fe-oxide-chlorite veins; white to cream, common orange-brown Fe-oxide } \\
\text { (limonite) stain, with rare vugs. Some veins contain dark green patches or mats of } \\
\text { chlorite. }\end{array}$ \\
\hline 05Z57B & 64.0878 & -148.7179 & 416243 & 7107736 & $06 \mathrm{~W}$ & $\begin{array}{l}\text { Quartz vein; milky white with weak to moderate limonite stains, some dark green } \\
\text { chlorite splotches, and vugs partially filled with psilomelane. }\end{array}$ \\
\hline 05Z62B & 64.0929 & -148.7266 & 415834 & 7108306 & $06 \mathrm{~W}$ & Quartz vein; maroon colored weathering, vuggy, quartz, Fe-oxide, and chlorite. \\
\hline 05Z64A & 64.0804 & -148.7280 & 415726 & 7106923 & $06 \mathrm{~W}$ & $\begin{array}{l}\text { Augen phyllite; (meta-graywacke), semi-schist texture, abundant white feldspar } \\
\text { porphyrocrysts, grayish quartz porphyrocrysts, in a white, black and green matrix, } \\
\text { with disseminated orange Fe-oxide spots and disseminated arsenopyrite. }\end{array}$ \\
\hline 05Z66B & 64.0786 & -148.7284 & 415700 & 7106716 & $06 \mathrm{~W}$ & $\begin{array}{l}\text { Quartz-tourmaline-scorodite vein; with discontinuous black tourmaline fractures, light } \\
\text { yellow-green powder (scorodite?) and no visible sulfides. }\end{array}$ \\
\hline
\end{tabular}




\begin{tabular}{|c|c|c|c|c|c|c|}
\hline Sample Number & Latitude & Longitude & UTM E & UTM N & Zone & Description \\
\hline 05Z68A & 64.0767 & -148.7318 & 415532 & 7106508 & $06 \mathrm{~W}$ & $\begin{array}{l}\text { Quartzite; (quartzite), light gray, light yellow, tan, orange-brown weathered surfaces, } \\
\text { competent, and highly siliceous. }\end{array}$ \\
\hline 05Z93A & 64.0763 & -148.6810 & 418006 & 7106398 & $06 \mathrm{~W}$ & $\begin{array}{l}\text { Quartz eye porphyry; white to light gray, compact, granular, highly Fe-oxide stained } \\
\text { orange-red, sucratic texture, and rare quartz eyes }(\leq 1 \mathrm{~mm}) \text {. }\end{array}$ \\
\hline 05Z107A & 64.0668 & -148.6546 & 419269 & 7105307 & $06 \mathrm{~W}$ & $\begin{array}{l}\text { Granite dike; tan to light yellow-brown weathering, light gray to light tan, sucratic } \\
\text { texture, fine grained sericitic phenocrysts, possibly altered hornblende, occasional } \\
\text { quartz phenocryst }(1 \mathrm{~mm}) \text {, with clots of disseminated pyrite and Fe-oxide after pyrite. }\end{array}$ \\
\hline 05Z108B & 64.0655 & -148.6579 & 419103 & 7105167 & $06 \mathrm{~W}$ & $\begin{array}{l}\text { Quartz-tourmaline-arsenopyrite-Fe-oxide vein; dark brown and orange, gossanous, } \\
\text { Fe-oxide stained, with patches of pale yellow staining and clots of discontinuous } \\
\text { patches of very fine grained arsenopyrite ( } 2-3 \text { percent up to } 7 \text { percent). }\end{array}$ \\
\hline 05Z114B & 64.0596 & -148.6787 & 418070 & 7104537 & $06 \mathrm{~W}$ & Quartz vein; white, with Fe-oxide on margins and as discontinuous clots. \\
\hline 05Z140C & 64.0009 & -148.6484 & 419380 & 7097957 & $06 \mathrm{~W}$ & $\begin{array}{l}\text { Quartz vein; white to orange-brown, vuggy with moderate to strong Fe-oxide stain, } \\
\text { and black Mn-oxide } \pm \text { Fe-oxide. }\end{array}$ \\
\hline 05Z180B & 64.0675 & -148.9453 & 405086 & 7105792 & $06 \mathrm{~W}$ & $\begin{array}{l}\text { Quartz vein; white, vuggy, slightly Fe-oxide stained orange (limonite), and rare } \\
\text { patches of very fine grained black materials. }\end{array}$ \\
\hline 05Z189A & 64.0720 & -148.9661 & 404088 & 7106326 & $06 \mathrm{~W}$ & $\begin{array}{l}\text { Quartz-feldspar vein; highly Fe-oxide stained, orange and brown, with quartz >> } \\
\text { feldspar, and yellow-orange-black Fe-oxide } \pm \mathrm{Mn} \text {-oxide. }\end{array}$ \\
\hline 05Z200B & 64.0789 & -148.9709 & 403878 & 7107095 & $06 \mathrm{~W}$ & $\begin{array}{l}\text { Quartz vein; white, mostly massive, weak Fe-oxide (limonite) stain, with occasional } \\
\text { orange-black moderate Fe-oxide stains. }\end{array}$ \\
\hline 05Z207B & 64.0774 & -148.9920 & 402847 & 7106960 & $06 \mathrm{~W}$ & $\begin{array}{l}\text { Quartz vein; discontinuous yellow to orange-brown stained, moderate Fe-oxide } \\
\text { (limonite). }\end{array}$ \\
\hline 05Z207C & 64.0774 & -148.9920 & 402847 & 7106960 & $06 \mathrm{~W}$ & $\begin{array}{l}\text { Phyllite; granulated, carbon, sheared, cemented and stained brown, and small white } \\
\text { acicular crystals (gypsum?). }\end{array}$ \\
\hline 05Z209C & 64.0773 & -148.9976 & 402570 & 7106958 & $06 \mathrm{~W}$ & Veins; white and canary yellow, with black streaks. \\
\hline 05Z217B & 64.1223 & -148.9829 & 403446 & 7111954 & $06 \mathrm{~W}$ & $\begin{array}{l}\text { Quartz vein; white to Fe-oxide orange, with black streaks and splotches of very fine } \\
\text { grained mineral that may be biotite. }\end{array}$ \\
\hline 05Z222B & 64.1195 & -148.9898 & 403097 & 7111648 & $06 \mathrm{~W}$ & $\begin{array}{l}\text { Quartz vein; white to gray, with Fe-oxide stain (orange), abundant large vugs partially } \\
\text { filled with subhedral quartz, limonite, and black very fine grained specks of oxidized } \\
\text { pyrite(?). Selvage is black chlorite. }\end{array}$ \\
\hline 05Z231A & 64.0057 & -148.6719 & 418244 & 7098529 & $06 \mathrm{~W}$ & $\begin{array}{l}\text { Quartz veined quartzite; dark gray, coarse grained, biotite bearing, with moderate Fe- } \\
\text { oxide staining (limonite). }\end{array}$ \\
\hline 05Z238B & 64.0741 & -148.7942 & 412479 & 7106307 & $06 \mathrm{~W}$ & $\begin{array}{l}\text { Quartz-tourmaline veins; white, gray, yellow, with patches, rosettes, and micro- } \\
\text { veinlets of tourmaline, with disseminated brown Fe-oxide spots. }\end{array}$ \\
\hline
\end{tabular}




\begin{tabular}{|c|c|c|c|c|c|l|}
\hline \multicolumn{7}{|l|}{ Table 1. (continued) } \\
\hline Sample Number & Latitude & Longitude & UTM E & UTM N & Zone & \multicolumn{1}{|l|}{ Description } \\
\hline \hline 05Z242A & 64.0718 & -148.7807 & 413129 & 7106032 & $06 \mathrm{~W}$ & $\begin{array}{l}\text { Quartz-tourmaline-Fe-oxide vein; white to gray, vuggy, with rosettes, patches, and } \\
\text { veinlets of black tourmaline. }\end{array}$ \\
\hline & & & & & & $\begin{array}{l}\text { Quartz-tourmaline-Fe-oxide vein; white, massive, with splotches, patches, and micro- } \\
\text { veinlets of black tourmaline, and orange Fe-oxide with disseminated orange-brown } \\
\text { 05Z252A }\end{array}$ \\
\hline & 64.0755 & -148.7597 & 414165 & 7106416 & $06 \mathrm{~W}$ & Fe-oxide grains. Fe-oxide replacing pyrite(?). \\
\hline 05Z253B & 64.0744 & -148.7647 & 413919 & 7106296 & $06 \mathrm{~W}$ & $\begin{array}{l}\text { Quartz-tourmaline vein; white, black, and occasionally orange, with micro-veinlets, } \\
\text { splotches, and patches of tourmaline and rosettes up to 3 mm thick. }\end{array}$ \\
\hline
\end{tabular}




\begin{tabular}{|c|c|c|c|c|c|c|c|c|c|c|c|c|c|c|c|c|c|c|c|}
\hline \multicolumn{20}{|c|}{ Note: $-=$ sample not analyzed for $\mathrm{Au}(+)$ or $\mathrm{Hg}, \mathrm{ppm}=$ parts per million, $\%=$ percent, $(\mathrm{Au}+)=$ see table 5.} \\
\hline Sample Number & $\mathrm{Au}$ & $\mathrm{Au}(+)$ & $\mathrm{Ag}$ & $\mathrm{Al}$ & As & $\mathrm{Ba}$ & $\mathrm{Be}$ & $\mathrm{Bi}$ & $\mathrm{Ca}$ & $\mathrm{Cd}$ & Co & $\mathrm{Cr}$ & $\mathrm{Cu}$ & $\mathrm{Fe}$ & $\mathrm{Hg}$ & $\mathrm{K}$ & $\mathrm{Mg}$ & $\mathrm{Mn}$ & Mo \\
\hline & ppm & ppm & ppm & $\%$ & $\mathrm{ppm}$ & $\mathrm{ppm}$ & ppm & $\mathrm{ppm}$ & $\%$ & ppm & $\mathrm{ppm}$ & $\mathrm{ppm}$ & ppm & $\%$ & ppm & $\%$ & $\%$ & $\mathrm{ppm}$ & ppm \\
\hline "05JEA30C & 0.014 & - & 0.9 & 7.66 & 3030 & 180 & 1.4 & 5 & 0.66 & $<0.5$ & 14 & \begin{tabular}{|l|}
177 \\
\end{tabular} & 65 & $\overline{\overline{5.54}}$ & " - & "5.10 & $\bar{~} 1.83$ & 114 & 10 \\
\hline 05JEA49A & $>10.0$ & 24.40 & 23.2 & 2.28 & 5570 & 370 & 0.6 & $<2$ & 0.05 & $<0.5$ & 1 & 19 & 39 & 1.35 & 0.59 & 1.42 & 0.11 & 441 & $<1$ \\
\hline O5JEA121B & 0.506 & - & $>100$ & 4.63 & 1735 & 80 & 1.5 & $<2$ & 0.07 & 7.1 & 2 & 27 & 186 & 13.60 & 0.59 & 0.12 & 0.64 & 236 & 3 \\
\hline 05JEA249A & 0.060 & - & 0.9 & 3.07 & 53 & 550 & 0.9 & $<2$ & 0.01 & $<0.5$ & 1 & 12 & 3 & 0.70 & 0.11 & 1.35 & 0.12 & 50 & $<1$ \\
\hline 05JEA254C & 0.009 & - & 0.6 & 5.66 & 35 & 1590 & 0.8 & $<2$ & 0.04 & 1.2 & 9 & 12 & 13 & 2.44 & - & 4.89 & 0.05 & 3540 & 1 \\
\hline 05JEA256C & 0.012 & - & $<0.5$ & 7.03 & 6 & 2380 & 0.9 & $<2$ & 0.02 & $<0.5$ & 2 & 11 & 4 & 0.60 & - & 5.48 & 0.07 & 194 & $<1$ \\
\hline 05JEA259A & $<0.005$ & - & $<0.5$ & 1.15 & 6 & 450 & 0.7 & $<2$ & 0.01 & 0.8 & 23 & 18 & 15 & 5.93 & - & 0.74 & 0.02 & 3530 & $<1$ \\
\hline 05LF39B & 0.005 & - & $<0.5$ & 4.01 & 26 & 430 & 3.0 & $<2$ & 0.25 & 0.5 & 3 & 27 & 7 & 2.03 & - & 1.22 & 0.34 & 134 & 2 \\
\hline 05LF40B & 0.005 & - & $<0.5$ & 5.72 & 226 & 1180 & 1.8 & $<2$ & 0.02 & 2.1 & 2 & 0 & 7 & 2.67 & - & 5.42 & 0.15 & 90 & 1 \\
\hline 05LF42B & 0.034 & - & 0.8 & 6.25 & 183 & 910 & 1.8 & $<2$ & 0.02 & $<0.5$ & 1 & 10 & 4 & 1.66 & 0.10 & 3.42 & 0.49 & 77 & 1 \\
\hline 05LF52A & 0.394 & - & 0.8 & 7.71 & 39 & 850 & 3.8 & $<2$ & 0.02 & $<0.5$ & 1 & 4 & 3 & 0.92 & 0.03 & 3.78 & 0.18 & 106 & $<1$ \\
\hline 05LF53B & 0.906 & - & 3.4 & 4.07 & 246 & 500 & 2.6 & 858 & 0.06 & 0.8 & 32 & 17 & 268 & 18.10 & 0.34 & 0.99 & 0.69 & 2010 & 1 \\
\hline 05LF57C & 0.011 & - & $<0.5$ & 5.68 & 26 & 3810 & 1.5 & 3 & 0.01 & $<0.5$ & $<1$ & 4 & 2 & 0.75 & - & 4.37 & 0.14 & 60 & 1 \\
\hline 05LF59B & 0.009 & - & $<0.5$ & 3.61 & 7 & 1340 & 0.6 & 5 & 0.11 & $<0.5$ & 1 & 18 & 2 & 0.68 & - & 3.21 & 0.10 & 64 & $<1$ \\
\hline 05LF61B & 0.026 & - & 63.4 & 7.26 & 844 & 1830 & 2.6 & $<2$ & 0.01 & $<0.5$ & 1 & 5 & 37 & 2.57 & 0.18 & 4.52 & 0.16 & 93 & 2 \\
\hline 05LF75B & $<0.005$ & - & 0.9 & 7.31 & 56 & 720 & 4.2 & $<2$ & 0.02 & $<0.5$ & $<1$ & 4 & 3 & 0.88 & - & 3.76 & 0.15 & 78 & $<1$ \\
\hline 05LF75C & 0.012 & - & 9.6 & 7.05 & 82 & 580 & 4.1 & $<2$ & 0.01 & $<0.5$ & $<1$ & 3 & 14 & 1.05 & - & 3.80 & 0.21 & 92 & 1 \\
\hline 05LF75E & 0.557 & - & 6.7 & 5.87 & 1940 & 850 & 3.8 & $<2$ & 0.07 & $<0.5$ & 3 & 16 & 4 & 3.48 & 0.10 & 0.82 & 0.91 & 54 & $<1$ \\
\hline 05LF77A & 6.140 & - & 14.3 & 3.07 & $>10000$ & 210 & 1.1 & 104 & 0.05 & $<0.5$ & 3 & 9 & 50 & 11.85 & 0.11 & 0.74 & 0.39 & 59 & 1 \\
\hline 05LF78A & 6.570 & - & 15.4 & 0.76 & $>10000$ & 50 & $<0.5$ & 112 & 0.05 & $<0.5$ & $<1$ & 2 & 13 & 16.95 & 0.04 & 0.04 & 0.15 & 17 & 1 \\
\hline 05LF79B & 2.770 & - & 15.8 & 3.87 & $>10000$ & 500 & 1.0 & 328 & 0.03 & $<0.5$ & 2 & 9 & 87 & 8.57 & 0.28 & 1.35 & 0.38 & 58 & 2 \\
\hline 05LF92A & 0.017 & - & 0.5 & 6.61 & 429 & 510 & 1.1 & $<2$ & 0.01 & $<0.5$ & 1 & 15 & 7 & 0.76 & 0.02 & 1.64 & 0.22 & 47 & $<1$ \\
\hline 05LF93B & 0.038 & - & $<0.5$ & 2.82 & 486 & 820 & 1.2 & $<2$ & 0.03 & $<0.5$ & $<1$ & 18 & 7 & 1.16 & 0.06 & 1.22 & 0.22 & 45 & $<1$ \\
\hline 05LF96A & 0.054 & - & 1.4 & 4.14 & 308 & 640 & 1.2 & $<2$ & 0.01 & $<0.5$ & 8 & 8 & 15 & 11.10 & 0.25 & 1.84 & 0.09 & 577 & $<1$ \\
\hline 05LF99A & $<0.005$ & - & $<0.5$ & 6.28 & 37 & 1060 & 1.6 & $<2$ & 0.36 & $<0.5$ & 2 & 13 & 4 & 1.85 & - & 2.70 & 0.46 & 230 & $<1$ \\
\hline 05LF113A & 0.029 & - & $<0.5$ & 4.38 & 44 & 350 & 1.4 & $<2$ & 0.01 & $<0.5$ & 1 & 4 & 6 & 0.97 & 0.05 & 2.37 & 0.17 & 61 & $<1$ \\
\hline 05LF140B & 0.013 & - & $<0.5$ & 5.82 & 1415 & 1000 & 0.7 & $<2$ & 0.02 & $<0.5$ & $<1$ & 11 & 4 & 1.22 & - & 5.33 & 0.11 & 27 & 1 \\
\hline 05LF141A & 0.048 & - & $<0.5$ & 2.27 & 139 & 190 & 0.6 & 4 & 0.01 & $<0.5$ & $<1$ & 13 & 4 & 0.86 & 0.86 & 0.93 & 0.09 & 32 & 3 \\
\hline 05LF141B & 0.108 & - & 0.9 & 2.28 & 338 & 140 & 0.6 & 2 & 0.01 & $<0.5$ & 1 & 11 & 9 & 1.39 & 3.56 & 0.91 & 0.09 & 37 & 5 \\
\hline 05LF160B & 2.040 & - & $<0.5$ & 7.58 & 1975 & 3440 & 0.6 & $<2$ & 0.02 & $<0.5$ & $<1$ & 8 & 4 & 0.56 & 0.03 & 4.79 & 0.06 & 17 & $<1$ \\
\hline 05LF171B & 0.013 & - & $<0.5$ & 4.03 & 22 & 900 & 4.2 & $<2$ & 0.03 & 1.3 & 31 & 6 & 4 & 22.70 & - & 2.49 & 0.22 & 1140 & 1 \\
\hline 05LF180A & 0.007 & - & $<0.5$ & 4.50 & 15 & 630 & 1.3 & $<2$ & 0.01 & $<0.5$ & $<1$ & 12 & 2 & 0.31 & 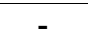 & 0.50 & 0.06 & 17 & 1 \\
\hline 05LF210A & $<0.005$ & 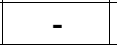 & $<0.5$ & 6.70 & 54 & 1010 & 1.4 & $<2$ & 0.12 & $<0.5$ & 1 & 12 & 13 & 1.34 & 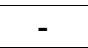 & 3.82 & 0.84 & 84 & 1 \\
\hline
\end{tabular}




\begin{tabular}{|c|c|c|c|c|c|c|c|c|c|c|c|}
\hline \multicolumn{12}{|c|}{ Table 2. (continued) } \\
\hline \multirow[t]{2}{*}{ Sample Number } & $\mathrm{Na}$ & $\mathrm{Ni}$ & $P$ & $\mathrm{~Pb}$ & $\mathrm{~S}$ & $\mathrm{Sb}$ & $\mathrm{Sr}$ & $\overline{\mathrm{Ti}}$ & $\mathrm{V}$ & W & $\mathrm{Zn}$ \\
\hline & $\%$ & ppm & ppm & ppm & $\%$ & ppm & ppm & $\%$ & ppm & ppm & ppm \\
\hline 05JEA30C & 0.53 & 34 & 160 & 14 & 2.78 & 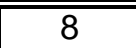 & 106 & 0.46 & 194 & $<10$ & 40 \\
\hline 05JEA49A & 0.03 & 3 & 200 & 1415 & 0.19 & 260 & 26 & 0.06 & 9 & $<10$ & 20 \\
\hline O5JEA121B & 0.42 & 8 & 410 & 1970 & 0.12 & 267 & 112 & 0.08 & 26 & $<10$ & 337 \\
\hline 05JEA249A & 0.03 & 3 & 80 & 42 & 0.05 & 24 & 22 & 0.08 & 10 & $<10$ & 9 \\
\hline 05JEA254C & 0.10 & 5 & 370 & 176 & $<0.01$ & $<5$ & 37 & 0.07 & 12 & $<10$ & 217 \\
\hline 05JEA256C & 0.10 & 3 & 240 & 111 & $<0.01$ & $<5$ & 23 & 0.09 & 20 & $<10$ & 59 \\
\hline 05JEA259A & 0.03 & 11 & 150 & 98 & 0.01 & $<5$ & 6 & 0.02 & 5 & $<10$ & 282 \\
\hline 05LF39B & 1.03 & 5 & 350 & 23 & 0.02 & $<5$ & 72 & 0.59 & 37 & 20 & 80 \\
\hline 05LF40B & 0.09 & 3 & 1130 & 13 & 0.08 & 15 & 43 & 0.08 & 6 & $<10$ & 145 \\
\hline 05LF42B & 0.35 & 2 & 220 & 235 & 0.32 & 396 & 50 & 0.12 & 17 & $<10$ & 31 \\
\hline 05LF52A & 0.08 & 2 & 110 & 5 & 0.01 & 128 & 62 & 0.08 & 5 & $<10$ & 10 \\
\hline 05LF53B & 0.30 & 15 & 960 & 425 & 0.02 & 66 & 81 & 0.06 & 54 & $<10$ & 89 \\
\hline 05LF57C & 0.22 & 2 & 60 & 38 & 0.02 & 28 & 37 & 0.04 & 2 & $<10$ & 14 \\
\hline 05LF59B & 0.38 & 2 & 510 & 8 & $<0.01$ & 8 & 51 & 0.05 & 2 & $<10$ & 7 \\
\hline 05LF61B & 0.08 & 3 & 960 & 4970 & 0.68 & 67 & 63 & 0.13 & 9 & $<10$ & 78 \\
\hline 05LF75B & 0.06 & $<1$ & 250 & 112 & 0.07 & 16 & 33 & 0.08 & 5 & $<10$ & 42 \\
\hline 05LF75C & 0.05 & $<1$ & 190 & 640 & 0.11 & 34 & 36 & 0.08 & 5 & $<10$ & 103 \\
\hline 05LF75E & 0.47 & 2 & 500 & 18 & 0.37 & 64 & 229 & 0.14 & 27 & $<10$ & 10 \\
\hline 05LF77A & 0.15 & 2 & 690 & 409 & 2.63 & 625 & 90 & 0.05 & 13 & $<10$ & 15 \\
\hline 05LF78A & 0.07 & 2 & 120 & 55 & 0.67 & 579 & 17 & 0.01 & 5 & $<10$ & 5 \\
\hline 05LF79B & 0.12 & 3 & 430 & 615 & 1.18 & 712 & 49 & 0.08 & 17 & $<10$ & 8 \\
\hline 05LF92A & 0.02 & 2 & 240 & 38 & 0.01 & 27 & 101 & 0.07 & 21 & $<10$ & 28 \\
\hline 05LF93B & 0.13 & 1 & 230 & 9 & 0.01 & 10 & 90 & 0.06 & 6 & $<10$ & 9 \\
\hline 05LF96A & 0.20 & 3 & 820 & 98 & 0.88 & 46 & 79 & 0.06 & 9 & $<10$ & 62 \\
\hline 05LF99A & 1.68 & 2 & 490 & 19 & $<0.01$ & 16 & 92 & 0.21 & 21 & $<10$ & 30 \\
\hline 05LF113A & 0.02 & 1 & 190 & 19 & $<0.01$ & 6 & 39 & 0.05 & 5 & $<10$ & 18 \\
\hline 05LF140B & 0.07 & 1 & 920 & 10 & 0.05 & 39 & 30 & 0.08 & 7 & 10 & 7 \\
\hline 05LF141A & 0.01 & 1 & 170 & 19 & 0.52 & 4470 & 14 & 0.03 & 3 & $<10$ & 3 \\
\hline 05LF141B & 0.01 & 3 & 510 & 49 & 2.32 & $>10000$ & 15 & 0.03 & 3 & $<10$ & 5 \\
\hline 05LF160B & 2.61 & 1 & 260 & 24 & 0.07 & 39 & 63 & 0.15 & 10 & $<10$ & 8 \\
\hline 05LF171B & 0.65 & 16 & 930 & 548 & 0.02 & 18 & 133 & 0.05 & 11 & $<10$ & 722 \\
\hline 05LF180A & 0.03 & 2 & 430 & 8 & $<0.01$ & 8 & 210 & 0.09 & 7 & 10 & 2 \\
\hline 05LF210A & 1.01 & 2 & 400 & 12 & 0.12 & 10 & 67 & 0.11 & 18 & $<10$ & 13 \\
\hline
\end{tabular}




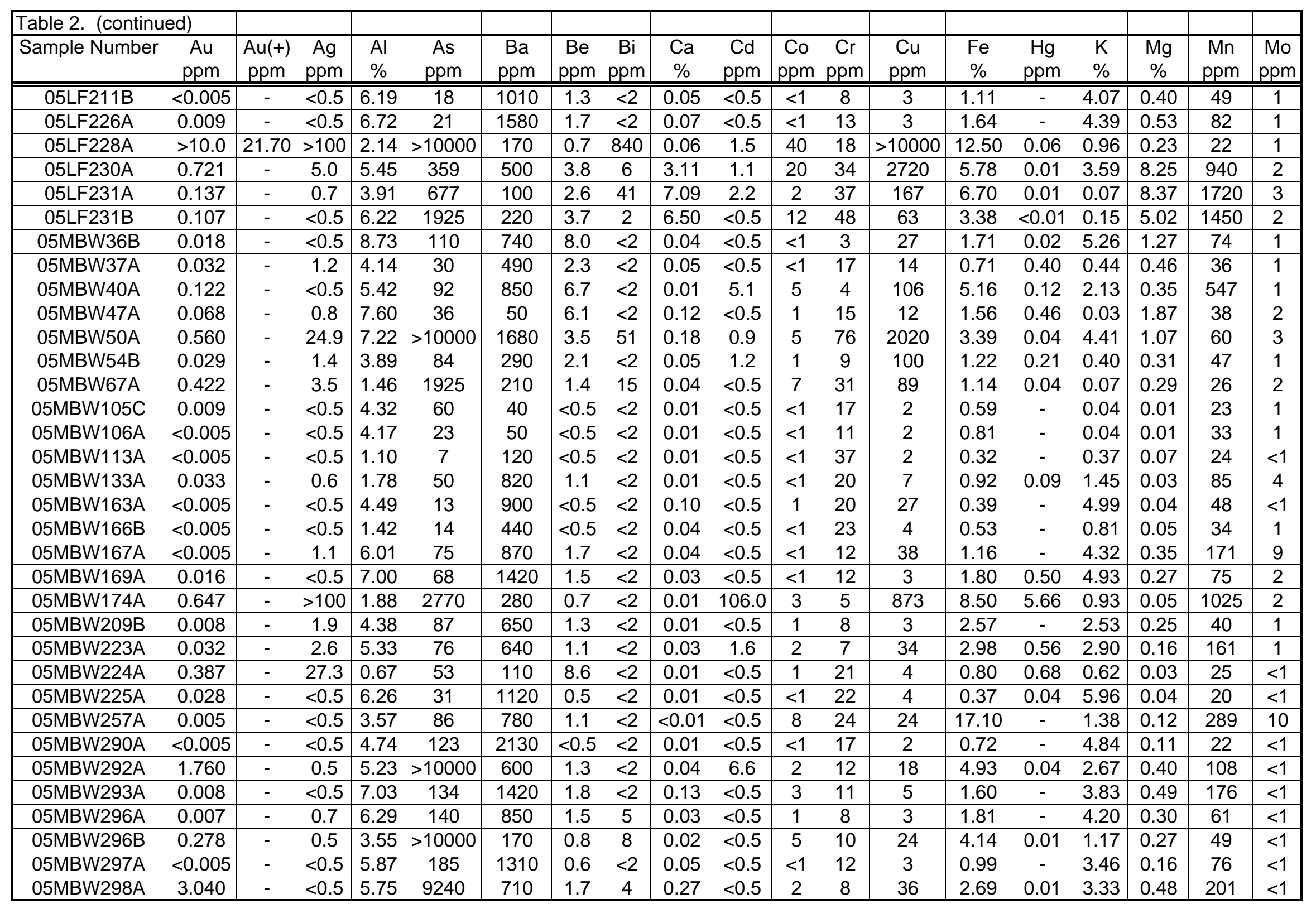




\begin{tabular}{|c|c|c|c|c|c|c|c|c|c|c|c|}
\hline \multicolumn{12}{|c|}{ Table 2. (continued) } \\
\hline Sample Number & $\mathrm{Na}$ & $\mathrm{Ni}$ & $\mathrm{P}$ & $\mathrm{Pb}$ & $\mathrm{S}$ & $\mathrm{Sb}$ & $\mathrm{Sr}$ & $\mathrm{Ti}$ & $\mathrm{V}$ & $\mathrm{W}$ & $\mathrm{Zn}$ \\
\hline & $\%$ & ppm & ppm & ppm & $\%$ & ppm & ppm & $\%$ & ppm & ppm & ppm \\
\hline 05LF211B & 0.79 & 1 & 430 & 15 & 0.18 & $<5$ & 38 & 0.10 & 13 & $<10$ & 17 \\
\hline 05LF226A & 0.69 & 3 & 450 & 16 & 0.02 & 16 & 47 & 0.24 & 25 & $<10$ & 32 \\
\hline 05LF228A & 0.28 & 11 & 410 & 69 & 4.28 & 538 & 29 & 0.06 & 38 & $<10$ & 12 \\
\hline 05LF230A & 0.30 & 125 & 450 & 6 & 0.41 & 9 & 147 & 0.29 & 112 & 280 & 110 \\
\hline 05LF231A & 0.24 & 41 & 210 & 7 & 1.86 & 12 & 205 & 0.27 & 108 & $<10$ & 326 \\
\hline 05LF231B & 0.57 & 35 & 340 & 8 & 1.15 & 7 & 329 & 0.37 & 121 & $<10$ & 83 \\
\hline 05MBW36B & 0.16 & 6 & 110 & 20 & 0.01 & 9 & 40 & 0.10 & 3 & $<10$ & 36 \\
\hline 05MBW37A & 0.15 & 3 & 320 & 110 & $<0.01$ & 9 & 100 & 0.05 & 7 & $<10$ & 29 \\
\hline 05MBW40A & 0.05 & 4 & 320 & 141 & 0.01 & 47 & 13 & 0.05 & 4 & 10 & 397 \\
\hline 05MBW47A & 0.70 & 8 & 160 & 47 & $<0.01$ & 30 & 48 & 0.07 & 11 & $<10$ & 27 \\
\hline 05MBW50A & 1.60 & 18 & 740 & 45 & 0.81 & 266 & 202 & 0.19 & 64 & 20 & 71 \\
\hline 05MBW54B & 0.11 & 10 & 240 & 48 & 0.01 & 23 & 34 & 0.04 & 13 & $<10$ & 56 \\
\hline 05MBW67A & 0.11 & 10 & 60 & 15 & 0.05 & 30 & 17 & 0.05 & 102 & 10 & 5 \\
\hline 05MBW105C & 3.47 & $<1$ & 60 & 19 & 0.08 & $<5$ & 37 & 0.03 & 2 & $<10$ & 5 \\
\hline 05MBW106A & 3.52 & 3 & 120 & 4 & 0.03 & $<5$ & 36 & 0.03 & 2 & $<10$ & 11 \\
\hline 05MBW113A & 0.41 & 1 & 10 & $<2$ & $<0.01$ & $<5$ & 17 & 0.01 & 1 & $<10$ & 3 \\
\hline 05MBW133A & 0.09 & 1 & 80 & 32 & 0.02 & 5 & 20 & 0.03 & 3 & $<10$ & 28 \\
\hline 05MBW163A & 0.10 & 1 & 500 & 9 & $<0.01$ & $<5$ & 64 & 0.04 & 1 & $<10$ & 34 \\
\hline 05MBW166B & 0.03 & 2 & 220 & 74 & 0.01 & $<5$ & 20 & 0.03 & 3 & $<10$ & 19 \\
\hline 05MBW167A & 0.27 & 1 & 620 & 1685 & 0.05 & $<5$ & 45 & 0.10 & 9 & $<10$ & 40 \\
\hline 05MBW169A & 0.09 & 1 & 1150 & 35 & 0.31 & 30 & 74 & 0.11 & 6 & $<10$ & 21 \\
\hline 05MBW174A & 0.01 & 2 & 1050 & $>10000$ & 4.27 & $>10000$ & 29 & 0.02 & 4 & $<10$ & 1040 \\
\hline 05MBW209B & 0.02 & 1 & 1680 & 185 & 0.59 & 216 & 39 & 0.09 & 12 & $<10$ & 14 \\
\hline 05MBW223A & 0.10 & 3 & 650 & 715 & 0.10 & 428 & 29 & 0.07 & 11 & $<10$ & 417 \\
\hline 05MBW224A & 0.01 & $<1$ & 490 & 204 & 0.19 & 20 & 12 & $<0.01$ & 1 & $<10$ & 7 \\
\hline 05MBW225A & 0.13 & $<1$ & 160 & 44 & 0.02 & 22 & 44 & 0.07 & 3 & $<10$ & 2 \\
\hline 05MBW257A & 0.05 & 49 & 2100 & 77 & 0.30 & 11 & 33 & 0.06 & 148 & $<10$ & 624 \\
\hline 05MBW290A & 0.07 & $<1$ & 110 & 95 & 0.09 & 47 & 83 & 0.15 & 6 & $<10$ & 21 \\
\hline 05MBW292A & 0.03 & $<1$ & 430 & 71 & 0.95 & 266 & 20 & 0.12 & 18 & 10 & 77 \\
\hline 05MBW293A & 1.06 & $<1$ & 490 & 47 & 0.57 & 11 & 56 & 0.13 & 16 & $<10$ & 21 \\
\hline 05MBW296A & 0.16 & $<1$ & 440 & 51 & 0.59 & 35 & 30 & 0.10 & 9 & 10 & 13 \\
\hline 05MBW296B & 0.10 & $<1$ & 230 & 38 & 1.89 & 200 & 9 & 0.04 & 5 & 10 & 5 \\
\hline 05MBW297A & 1.90 & $<1$ & 190 & 23 & 0.22 & 9 & 86 & 0.07 & 7 & $<10$ & 14 \\
\hline 05MBW298A & 0.14 & 1 & 880 & 32 & 0.79 & 48 & 22 & 0.10 & 16 & $<10$ & 17 \\
\hline
\end{tabular}




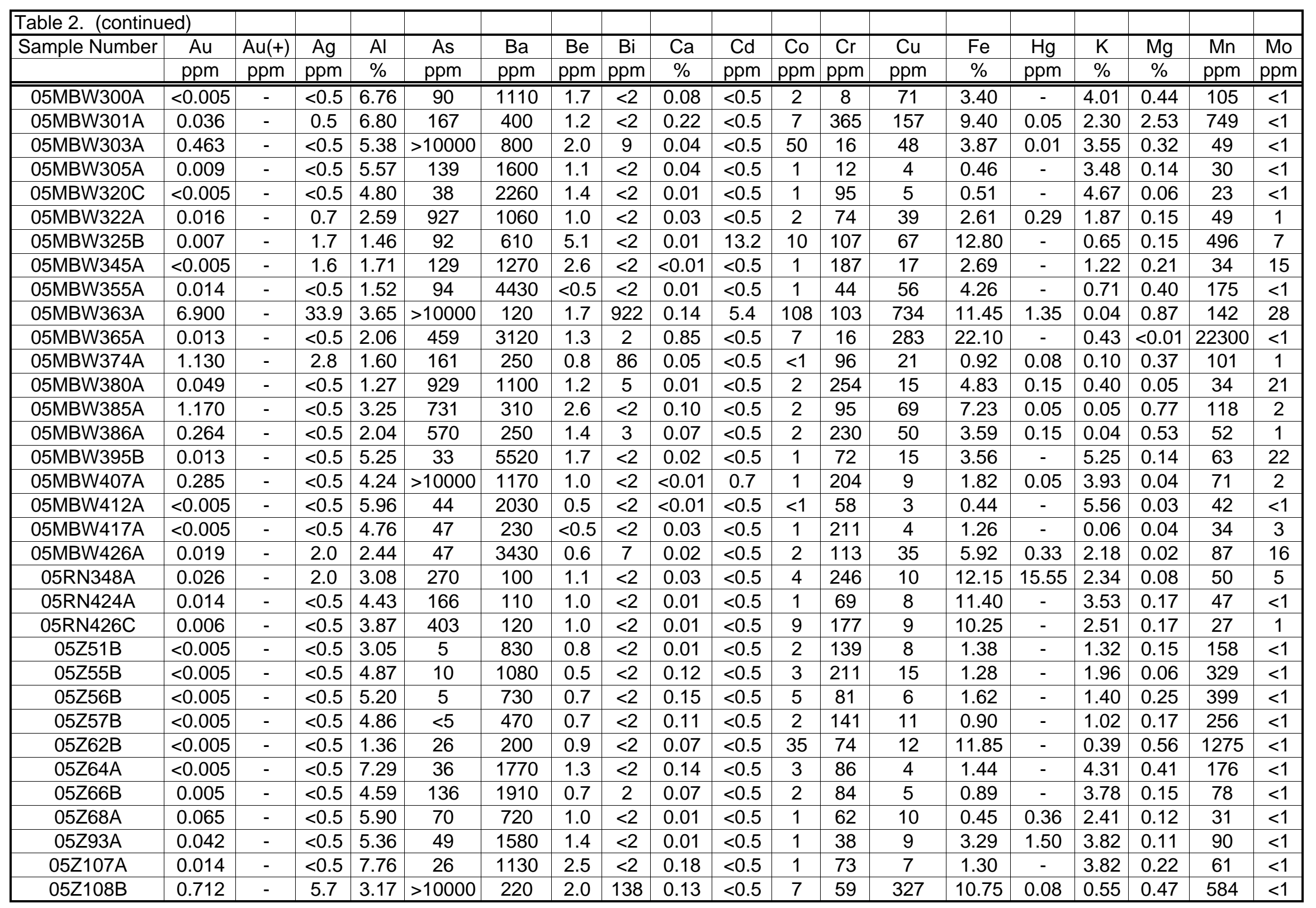




\begin{tabular}{|c|c|c|c|c|c|c|c|c|c|c|c|}
\hline \multicolumn{12}{|c|}{ Table 2. (continued) } \\
\hline Sample Number & $\mathrm{Na}$ & $\mathrm{Ni}$ & $\mathrm{P}$ & $\mathrm{Pb}$ & $\mathrm{S}$ & $\mathrm{Sb}$ & $\mathrm{Sr}$ & $\mathrm{Ti}$ & $\mathrm{V}$ & $\mathrm{W}$ & $\mathrm{Zn}$ \\
\hline & $\%$ & ppm & ppm & ppm & $\%$ & ppm & ppm & $\%$ & ppm & ppm & ppm \\
\hline 05MBW300A & 1.05 & $<1$ & 830 & 48 & 0.12 & 9 & 76 & 0.15 & 18 & 10 & 29 \\
\hline 05MBW301A & 0.02 & 94 & 1380 & 257 & 1.09 & 254 & 38 & 0.20 & 114 & 10 & 70 \\
\hline 05MBW303A & 0.79 & 6 & 410 & 67 & 1.33 & 107 & 66 & 0.04 & 16 & $<10$ & 6 \\
\hline 05MBW305A & 0.11 & $<1$ & 210 & 24 & 0.08 & 34 & 91 & 0.11 & 7 & 10 & 3 \\
\hline 05MBW320A & 0.31 & 4 & 80 & 11 & $<0.01$ & 6 & 41 & 0.07 & 2 & $<10$ & 24 \\
\hline 05MBW322A & 0.11 & 2 & 190 & 14 & 0.36 & 65 & 43 & 0.04 & 2 & $<10$ & 15 \\
\hline 05MBW325B & 0.01 & 156 & 2670 & 17 & 0.05 & 42 & 25 & 0.05 & 352 & $<10$ & 1335 \\
\hline 05MBW345A & 0.01 & 11 & 450 & 20 & 0.70 & 18 & 38 & 0.08 & 509 & $<10$ & 12 \\
\hline 05MBW355A & 0.02 & 7 & 590 & 18 & 0.27 & 64 & 54 & 0.06 & 68 & $<10$ & 21 \\
\hline 05MBW363A & 0.36 & 22 & 1710 & 2710 & 5.39 & $>10000$ & 98 & 0.07 & 141 & $<10$ & 217 \\
\hline 05MBW365A & 0.02 & 106 & $>10000$ & 48 & 0.31 & 369 & 124 & 0.02 & 35 & 10 & 321 \\
\hline 05MBW374A & 0.11 & 3 & 110 & 59 & 0.01 & 119 & 34 & 0.09 & 64 & 10 & 3 \\
\hline 05MBW380A & 0.03 & 14 & 2260 & 43 & 0.25 & 849 & 12 & 0.10 & 1070 & $<10$ & 9 \\
\hline 05MBW385A & 0.28 & 7 & 1280 & 43 & 0.01 & 157 & 92 & 0.13 & 187 & 10 & 30 \\
\hline 05MBW386A & 0.18 & 6 & 240 & 21 & 0.01 & 124 & 40 & 0.09 & 72 & 10 & 23 \\
\hline 05MBW395B & 0.09 & 2 & 720 & 15 & 0.13 & 25 & 31 & 0.08 & 14 & $<10$ & 86 \\
\hline 05MBW407A & 0.25 & 4 & 1660 & 47 & 0.27 & 126 & 35 & 0.06 & 2 & 10 & 41 \\
\hline 05MBW412A & 0.10 & 4 & 50 & 10 & $<0.01$ & $<5$ & 65 & 0.05 & 1 & $<10$ & 3 \\
\hline 05MBW417A & 3.81 & 4 & 260 & 10 & 0.10 & 7 & 63 & 0.07 & 42 & $<10$ & 42 \\
\hline 05MBW426A & 0.05 & 20 & 710 & 57 & 0.12 & 41 & 30 & 0.02 & 17 & $<10$ & 311 \\
\hline 05RN348A & 0.05 & $<1$ & 60 & 104 & $>10.0$ & 31 & 40 & 0.04 & 5 & $<10$ & 7 \\
\hline 05RN424A & 0.57 & $<1$ & 70 & 77 & $>10.0$ & 25 & 28 & 0.05 & 7 & $<10$ & 27 \\
\hline 05RN426C & 0.02 & 8 & 120 & 40 & $>10.0$ & 36 & 16 & 0.04 & 5 & $<10$ & 8 \\
\hline 05Z51B & 0.97 & 3 & 50 & 30 & 0.06 & $<5$ & 32 & 0.07 & 14 & $<10$ & 14 \\
\hline 05Z55B & 2.19 & 3 & 600 & 148 & 0.03 & $<5$ & 53 & 0.07 & 6 & $<10$ & 177 \\
\hline 05Z56B & 2.45 & 6 & 630 & 54 & 0.01 & $<5$ & 77 & 0.14 & 15 & $<10$ & 56 \\
\hline 05Z57B & 2.72 & 7 & 450 & 23 & $<0.01$ & $<5$ & 92 & 0.09 & 9 & 10 & 16 \\
\hline 05Z62B & 0.02 & 22 & 640 & 4 & $<0.01$ & $<5$ & 7 & 0.25 & 87 & $<10$ & 73 \\
\hline 05Z64A & 1.03 & 2 & 630 & 17 & 0.01 & 8 & 91 & 0.16 & 23 & 10 & 20 \\
\hline 05Z66B & 0.11 & 1 & 570 & 20 & 0.06 & 12 & 79 & 0.09 & 8 & $<10$ & 10 \\
\hline 05Z68A & 0.06 & 1 & 210 & 27 & 0.03 & 41 & 126 & 0.15 & 13 & 20 & 3 \\
\hline 05Z93A & 0.07 & $<1$ & 230 & 32 & 0.36 & 26 & 46 & 0.09 & 4 & $<10$ & 15 \\
\hline 05Z107A & 2.18 & 6 & 330 & 22 & $<0.01$ & 20 & 369 & 0.10 & 21 & $<10$ & 31 \\
\hline 05Z108B & 0.26 & 1 & 520 & 72 & 0.98 & 117 & 126 & 0.04 & 10 & 10 & 44 \\
\hline
\end{tabular}




\begin{tabular}{|c|c|c|c|c|c|c|c|c|c|c|c|c|c|c|c|c|c|c|c|}
\hline \multicolumn{20}{|c|}{ Table 2. (continued) } \\
\hline Sample Number & $\mathrm{Au}$ & $\mathrm{Au}(+)$ & $\mathrm{Ag}$ & $\mathrm{Al}$ & As & $\mathrm{Ba}$ & $\mathrm{Be}$ & $\mathrm{Bi}$ & $\mathrm{Ca}$ & $\mathrm{Cd}$ & Co & $\mathrm{Cr}$ & $\mathrm{Cu}$ & $\mathrm{Fe}$ & $\mathrm{Hg}$ & $\mathrm{K}$ & $\mathrm{Mg}$ & $\mathrm{Mn}$ & Mo \\
\hline & ppm & $\mathrm{ppm}$ & ppm & $\%$ & ppm & ppm & ppm & $\mathrm{ppm}$ & $\%$ & ppm & $\mathrm{ppm}$ & $\mathrm{ppm}$ & ppm & $\%$ & ppm & $\%$ & $\%$ & ppm & ppm \\
\hline 05Z114B & $<0.005$ & 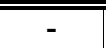 & $<<0.5$ & 2.32 & 123 & $\overline{590}$ & $\overline{1.7}$ & "<2 & 0.01 & 0.8 & 17 & 2229 & 11 & 6.63 & - & 1.58 & 0.16 & 395 & $<<1$ \\
\hline 05Z140C & $<0.005$ & - & $<0.5$ & 0.29 & 131 & 70 & $<0.5$ & $<2$ & 0.05 & $<0.5$ & 17 & 102 & 10 & 5.42 & - & 0.08 & 0.01 & 1205 & $<1$ \\
\hline 05Z180B & $<0.005$ & - & $<0.5$ & 3.63 & 17 & 270 & $<0.5$ & $<2$ & 0.01 & $<0.5$ & 2 & 193 & 4 & 0.61 & - & 0.55 & 0.12 & 43 & $<1$ \\
\hline 05Z189A & $<0.005$ & - & $<0.5$ & 5.43 & 21 & 1930 & 0.9 & $<2$ & 0.01 & $<0.5$ & 2 & 77 & 6 & 1.62 & - & 5.87 & 0.08 & 94 & $<1$ \\
\hline 05Z200B & $<0.005$ & - & $<0.5$ & 5.73 & 11 & 3700 & 0.8 & $<2$ & $<0.01$ & $<0.5$ & 2 & 190 & 30 & 0.94 & - & 5.95 & 0.16 & 165 & $<1$ \\
\hline 05Z207B & 0.005 & - & 1.2 & 4.68 & 33 & 1190 & 2.6 & $<2$ & 0.19 & 0.5 & 2 & 168 & 12 & 1.86 & - & 2.52 & 0.35 & 128 & 11 \\
\hline 05Z207C & $<0.005$ & - & 0.6 & 2.94 & 162 & 1170 & 2.5 & $<2$ & 0.79 & 0.9 & 1 & 156 & 26 & 3.08 & - & 1.40 & 0.36 & 83 & 12 \\
\hline 05Z209C & $<0.005$ & - & 0.7 & 5.01 & 465 & 7090 & 2.1 & $<2$ & 0.01 & 0.7 & 11 & 160 & 11 & 2.74 & - & 4.05 & 0.26 & 1515 & 12 \\
\hline 05Z217B & $<0.005$ & - & $<0.5$ & 4.25 & 13 & 1500 & 0.6 & $<2$ & 0.05 & $<0.5$ & 5 & 194 & 3 & 1.22 & - & 1.54 & 0.05 & 578 & $<1$ \\
\hline 05Z222B & $<0.005$ & - & $<0.5$ & 4.79 & 14 & 270 & 0.6 & $<2$ & 0.02 & $<0.5$ & 1 & 80 & 5 & 0.75 & - & 0.53 & 0.05 & 57 & $<1$ \\
\hline 05Z231A & $<0.005$ & - & $<0.5$ & 0.48 & $<5$ & 260 & $<0.5$ & $<2$ & 0.01 & $<0.5$ & $<1$ & 208 & 4 & 0.90 & - & 0.15 & 0.01 & 26 & 4 \\
\hline 05Z238B & 0.010 & - & $<0.5$ & 3.39 & 10 & 770 & 0.7 & $<2$ & 0.01 & $<0.5$ & 1 & 95 & 6 & 0.78 & - & 2.17 & 0.09 & 60 & $<1$ \\
\hline 05Z242A & 0.060 & - & $<0.5$ & 4.62 & 26 & 3900 & 2.3 & 7 & 0.04 & $<0.5$ & 5 & 141 & 49 & 2.00 & 0.03 & 2.48 & 0.48 & 140 & 6 \\
\hline 05Z252A & 0.017 & - & $<0.5$ & 1.97 & 5 & 320 & 0.7 & $<2$ & 0.02 & $<0.5$ & 1 & 97 & 12 & 0.93 & 0.01 & 0.68 & 0.14 & 63 & 1 \\
\hline 05Z253B & 0.065 & - & $<0.5$ & 3.36 & 7 & 300 & 1.2 & 3 & 0.03 & $<0.5$ & 1 & 194 & 8 & 0.77 & 0.02 & 1.09 & 0.36 & 56 & 2 \\
\hline
\end{tabular}




\begin{tabular}{|c|c|c|c|c|c|c|c|c|c|c|c|}
\hline \multicolumn{2}{|l}{ Table 2. (continued) } & & & & & & & & & & \\
\hline Sample Number & $\mathrm{Na}$ & $\mathrm{Ni}$ & $\mathrm{P}$ & $\mathrm{Pb}$ & $\mathrm{S}$ & $\mathrm{Sb}$ & $\mathrm{Sr}$ & $\mathrm{Ti}$ & $\mathrm{V}$ & $\mathrm{W}$ & $\mathrm{Zn}$ \\
\hline & $\%$ & $\mathrm{ppm}$ & $\mathrm{ppm}$ & $\mathrm{ppm}$ & $\%$ & $\mathrm{ppm}$ & $\mathrm{ppm}$ & $\%$ & $\mathrm{ppm}$ & $\mathrm{ppm}$ & $\mathrm{ppm}$ \\
\hline \hline 05Z114B & 0.11 & 11 & 240 & 77 & 0.01 & 5 & 38 & 0.04 & 6 & 20 & 121 \\
\hline 05Z140C & 0.01 & 6 & 780 & 61 & 0.01 & $<5$ & 7 & $<0.01$ & 2 & $<10$ & 81 \\
\hline 05Z180B & 2.06 & 1 & 120 & 22 & $<0.01$ & $<5$ & 53 & 0.06 & 4 & $<10$ & 7 \\
\hline 05Z189A & 0.10 & 2 & 150 & 17 & 0.01 & $<5$ & 31 & 0.05 & 9 & $<10$ & 24 \\
\hline 05Z200B & 0.08 & 4 & 210 & 307 & $<0.01$ & $<5$ & 47 & 0.14 & 14 & $<10$ & 39 \\
\hline 05Z207B & 0.26 & 18 & 3970 & 19 & 0.22 & 13 & 46 & 0.24 & 260 & $<10$ & 31 \\
\hline 05Z207C & 0.01 & 36 & $>10000$ & 9 & 0.40 & 161 & 44 & 0.13 & 281 & $<10$ & 57 \\
\hline 05Z209C & 0.06 & 5 & 5490 & 33 & 0.10 & 12 & 29 & 0.38 & 184 & 10 & 49 \\
\hline 05Z217B & 1.91 & 6 & 350 & 15 & $<0.01$ & $<5$ & 71 & 0.10 & 12 & $<10$ & 18 \\
\hline 05Z222B & 3.19 & 1 & 60 & 13 & $<0.01$ & $<5$ & 64 & 0.08 & 6 & $<10$ & 5 \\
\hline 05Z231A & 0.02 & 4 & 130 & 7 & $<0.01$ & $<5$ & 42 & 0.01 & 31 & $<10$ & $<2$ \\
\hline 05Z238B & 0.08 & 1 & 50 & 12 & $<0.01$ & $<5$ & 24 & 0.05 & 4 & 20 & 4 \\
\hline 05Z242A & 0.31 & 5 & 210 & 35 & 0.01 & 11 & 73 & 0.05 & 13 & 20 & 13 \\
\hline 05Z252A & 0.06 & 4 & 90 & 13 & $<0.01$ & $<5$ & 37 & 0.02 & 5 & $<10$ & 10 \\
\hline 05Z253B & 0.14 & 6 & 80 & 31 & $<0.01$ & 24 & 29 & 0.06 & 12 & 10 & 5 \\
\hline
\end{tabular}




\begin{tabular}{|c|c|c|c|c|c|c|}
\hline Sample Number & Latitude & Longitude & UTM E & UTM N & Zone & Description \\
\hline 05JEA1A & 64.0501 & -148.8532 & 409523 & 7103721 & 06W & $\begin{array}{l}\text { Phyllite; (meta-graywacke), dark brown, locally competent, with } 15 \text { percent relict } \\
\text { feldspar phenocrysts }(0.1-1 \mathrm{~mm} \text { ) in lenses. LB001 core sample } 217.5 \text { to } 218 \text { feet. } \\
\text { Industry map unit "Lower tuff". (Location accuracy, } \pm 30 \mathrm{~m} \text { ). }\end{array}$ \\
\hline 05JEA2A & 64.0501 & -148.8532 & 409523 & 7103721 & 06W & $\begin{array}{l}\text { Meta-mafic; (meta-mafic), sugary, brown, fine grained, with bands of massive green } \\
\text { actinolite. Chalcopyrite (trace) + actinolite }+ \text { pyrrhotite veins. LB001 core sample, } \\
\text { 201-202 feet. (Location accuracy, } \pm 30 \text { m). }\end{array}$ \\
\hline 05JEA4A & 64.0492 & -148.8535 & 409508 & 7103612 & 06W & $\begin{array}{l}\text { Phyllite; (meta-graywacke), brown, massive to phyllitic, with } 35 \text { percent relict } \\
\text { feldspar phenocrysts }(2-3 \mathrm{~mm} \text { ) and } 3 \text { percent wispy pyrrhotite. LB011 core sample, } \\
270.5-271 \text { feet. Industry map unit "Dacite crystal tuff". (Location accuracy, } \pm 30 \\
\text { m). }\end{array}$ \\
\hline 05JEA5A & 64.0430 & -148.8527 & 409526 & 7102925 & 06W & $\begin{array}{l}\text { Phyllite; (meta-mafic, carbonate altered), laminated, with biotite and calcite. Acicular } \\
\text { actinolite in calcite lenses. LBG } 24 \text { core sample, } 38-54 \text { feet. Industry map unit "Eva } \\
\text { Creek phyllite". (Location accuracy, } \pm 100 \mathrm{~m} \text { ). }\end{array}$ \\
\hline 05JEA6A & 64.0379 & -148.8603 & 409139 & 7102370 & 06W & $\begin{array}{l}\text { Porphyry; (granite) tan to white, with } 5-10 \text { percent euhedral, smoky quartz }(2-3 \mathrm{~mm}) \\
\text { and } 15-20 \text { percent white, clay-altered feldspar crystals in a yellowish tan, creamy } \\
\text { matrix with } 1-2 \text { percent black tourmaline as splays. LBG } 25 \text { core sample, 91.5-92 } \\
\text { feet. (Location accuracy, } \pm 100 \mathrm{~m}) \text {. }\end{array}$ \\
\hline 05JEA11A & 64.0668 & -148.8054 & 411909 & 7105514 & 06W & $\begin{array}{l}\text { Phyllite; (meta-graywacke), slightly foliated, porphyritic, with } 67.5 \text { percent relict } \\
\text { feldspar }(<5 \mathrm{~mm}) \text { and } 15 \text { percent gray relict quartz }(2 \mathrm{~mm}) \text { phenocrysts. }\end{array}$ \\
\hline 05JEA12A & 64.0660 & -148.8030 & 412027 & 7105418 & 06W & $\begin{array}{l}\text { Granodiorite dike; (granodiorite), medium to coarse grained, with } 7 \text { percent biotite (1 } \\
\mathrm{mm}), 5 \text { percent hornblende (5 mm long), and potassium feldspar crystals up to } 2 \mathrm{~cm} \\
\text { long. }\end{array}$ \\
\hline 05JEA18A & 64.0616 & -148.7777 & 413245 & 7104892 & 06W & $\begin{array}{l}\text { Phyllite; (meta-graywacke), massive, foliated, fine to medium grained, with sericite, } \\
\text { quartz crystals }(2-5 \mathrm{~mm}) \text {, feldspar ( } 2 \mathrm{~mm} \text { average), and trace biotite in dark brown } \\
\text { lenses. }\end{array}$ \\
\hline 05JEA23A & 64.0599 & -148.7593 & 414137 & 7104680 & 06W & $\begin{array}{l}\text { Phyllite; (meta-graywacke), foliated, with quartz + sericite + feldspar crystals. Quartz } \\
\text { and feldspar crystals up to } 4 \mathrm{~mm} \text { in diameter ( } 2 \mathrm{~mm} \text { average). }\end{array}$ \\
\hline 05JEA24A & 64.0615 & -148.7509 & 414551 & 7104851 & 06W & $\begin{array}{l}\text { Phyllite; (meta-graywacke), light green, with quartz }(<7 \mathrm{~mm}) \text {, interstitial or sheared } \\
\text { out feldspar, with larger white mica crystals. }\end{array}$ \\
\hline 05JEA25A & 64.0611 & -148.7491 & 414639 & 7104797 & 06W & $\begin{array}{l}\text { Phyllite; (meta-graywacke), red weathered, vuggy, medium grained, with } 5 \text { percent } \\
\text { quartz (2-4 mm), feldspar, and sericite. }\end{array}$ \\
\hline 05JEA26A & 64.0611 & -148.7446 & 414859 & 7104793 & 06W & $\begin{array}{l}\text { Phyllite; (meta-graywacke), light green, foliated, medium grained, with quartz, } \\
\text { feldspar, and white mica. }\end{array}$ \\
\hline
\end{tabular}




\begin{tabular}{|c|c|c|c|c|c|c|}
\hline Sample Number & Latitude & Longitude & UTM E & UTM N & Zone & Description \\
\hline 05JEA27A & 64.0577 & -148.7443 & 414863 & 7104410 & $06 \mathrm{~W}$ & $\begin{array}{l}\text { Phyllite; (meta-rhyolite), light to medium green, massive to phyllitic, medium grained, } \\
\text { with } 25 \text { percent feldspar crystals }(2-3 \mathrm{~mm}) \text {. }\end{array}$ \\
\hline 05JEA30A & 64.0293 & -148.9464 & 404906 & 7101536 & $06 \mathrm{~W}$ & $\begin{array}{l}\text { Granite dike; (granodiorite), 8-feet-thick, biotite granite dike, with secondary biotite. } \\
\text { Dike emplaced sub-parallel to foliation. }\end{array}$ \\
\hline 05JEA33A & 64.0719 & -148.8193 & 411249 & 7106093 & $06 \mathrm{~W}$ & $\begin{array}{l}\text { Phyllite; (meta-granite), well foliated, medium to coarse grained, with quartz and } \\
\text { feldspar crystals in layers segregated by crystal size }(2-10 \mathrm{~mm}) \text {. }\end{array}$ \\
\hline 05JEA37A & 64.0774 & -148.8219 & 411141 & 7106714 & $06 \mathrm{~W}$ & $\begin{array}{l}\text { Semi-schist; (meta-graywacke), medium grained, with } 70 \text { percent feldspar crystals (3 } \\
4 \mathrm{~mm} \text { ) and little or no quartz eyes. }\end{array}$ \\
\hline 05JEA38B & 64.0789 & -148.8229 & 411094 & 7106884 & $06 \mathrm{~W}$ & $\begin{array}{l}\text { Phyllite; (meta-graywacke), light colored, fine- to very fine-grained, friable layers, with } \\
\text { quartz, feldspar, and sericite. Recessively weathering. }\end{array}$ \\
\hline 05JEA45A & 64.0767 & -148.8521 & 409664 & 7106682 & $06 \mathrm{~W}$ & $\begin{array}{l}\text { Phyllite/semi-schist; (meta-graywacke), green, well foliated, medium grained, with } 5 \\
\text { percent quartz eyes }(\leq 4 \mathrm{~mm}), 45 \text { percent feldspar crystals }(\leq 4 \mathrm{~mm}) \text {, chlorite, and } \\
\text { sericite. }\end{array}$ \\
\hline 05JEA47A & 64.0702 & -148.8626 & 409129 & 7105971 & $06 \mathrm{~W}$ & $\begin{array}{l}\text { Phyllite; (meta-graywacke), finely foliated layers of quartz, feldspar, and sericite, with } \\
\text { pieces of quartz vein and a few pieces of blocky semi-schist with quartz eyes }(2 \mathrm{~mm}) \\
\text { and feldspar crystals ( } 5 \mathrm{~mm} \text { ). In frost boils. }\end{array}$ \\
\hline 05JEA54A & 64.0698 & -148.8781 & 408372 & 7105947 & $06 \mathrm{~W}$ & $\begin{array}{l}\text { Phyllite; (meta-granite), light green, fine grained, thinly parting, with quartz, feldspar, } \\
\text { and sericite. }\end{array}$ \\
\hline 05JEA64B & 64.0626 & -148.8508 & 409684 & 7105105 & 06W & $\begin{array}{l}\text { Phyllite; (meta-granite), pale green, foliated, medium to coarse grained, with } 20 \\
\text { percent quartz eyes }(<2-4 \mathrm{~mm}) \text { and } 20 \text { percent feldspar crystals }(<3-4 \mathrm{~mm}) \text {. Some } \\
\text { feldspar altered to yellow clay. }\end{array}$ \\
\hline 05JEA77A & 64.0756 & -148.8069 & 411864 & 7106494 & $06 \mathrm{~W}$ & $\begin{array}{l}\text { Phyllite; (meta-granite), foliated, slabby breaking, medium grained, with } 30 \text { percent } \\
\text { quartz + feldspar crystals }(2-3 \mathrm{~mm}) \text {. }\end{array}$ \\
\hline 05JEA82A & 64.0722 & -148.6516 & 419427 & 7105905 & $06 \mathrm{~W}$ & $\begin{array}{l}\text { Schist; (meta-graywacke), gray weathered; local, bright-red, iron-oxide staining; } 85 \\
\text { percent crystalline; medium grained; with } 13 \text { percent quartz and } 70 \text { percent feldspar } \\
\text { crystals in a well foliated matrix of chlorite(?) and white mica. 3-inch-wide quartz } \\
\text { vein sub-parallel to foliation. }\end{array}$ \\
\hline 05JEA84A & 64.0733 & -148.6468 & 419668 & 7106024 & $06 \mathrm{~W}$ & $\begin{array}{l}\text { Schist; (meta-graywacke), foliated, medium grained, with } 20 \text { percent rotated quartz } \\
\text { augens }(3 \mathrm{~mm}), 30 \text { percent feldspar }(3-4 \mathrm{~mm}) \text {, and chlorite + white mica that is } \\
\text { darker gray in foliation planes. }\end{array}$ \\
\hline 05JEA99A & 64.0924 & -148.6573 & 419207 & 7108168 & $06 \mathrm{~W}$ & $\begin{array}{l}\text { Schist; (meta-graywacke), greenish gray, very friable, medium grained, } 60 \text { percent } \\
\text { quartz + feldspar crystals }(3 \mathrm{~mm}) \text { with chlorite and white mica. }\end{array}$ \\
\hline 05JEA109A & 64.0775 & -148.6024 & 421842 & 7106436 & $06 \mathrm{~W}$ & $\begin{array}{l}\text { Schist; (meta-graywacke), foliated, medium grained, with } 12 \text { percent quartz eyes (4- } \\
5 \mathrm{~mm}), 15 \text { percent feldspar eyes, minor chlorite(?), and sericite. }\end{array}$ \\
\hline
\end{tabular}




\begin{tabular}{|c|c|c|c|c|c|c|}
\hline Sample Number & Latitude & Longitude & UTM E & UTM N & Zone & Description \\
\hline 05JEA112A & 64.0786 & -148.6089 & 421532 & 7106572 & 06W & $\begin{array}{l}\text { Schist; (meta-graywacke), medium to coarse grained, with } 80 \text { percent quartz + } \\
\text { feldspar crystals ( } 4 \mathrm{~mm} \text { long). }\end{array}$ \\
\hline 05JEA141A & 64.1235 & -148.8903 & 407957 & 7111943 & 06W & $\begin{array}{l}\text { Schist; (meta-granite), coarse to very coarse grained, with } 40 \text { percent quartz eyes ( } 3 \\
\mathrm{~mm}), 10 \text { percent feldspar }(1.5 \mathrm{~cm}) \text {, chlorite(?), and white mica. }\end{array}$ \\
\hline 05JEA166A & 64.0519 & -148.7367 & 415217 & 7103756 & 06W & $\begin{array}{l}\text { Schist; (meta-granite), foliated, coarse-grained, with } 20 \text { percent relict quartz } \\
\text { phenocrysts (3-4 mm), } 70 \text { percent relict feldspar phenocrysts }(4-5 \mathrm{~mm} \text {; sheared out } \\
\text { in foliation), and white mica. }\end{array}$ \\
\hline 05JEA174A & 64.1082 & -148.5149 & 426191 & 7109754 & 06W & $\begin{array}{l}\text { Schist; (meta-graywacke), gray, foliated, medium to coarse grained, with } 10 \text { percent } \\
\text { quartz crystals }(<4 \mathrm{~mm}), 30 \text { percent feldspar crystals [2-3 mm; sheared out(?)], }\end{array}$ \\
\hline 05JEA183A & 64.0394 & -148.5293 & 425308 & 7102106 & 06W & $\begin{array}{l}\text { Schist; (meta-graywacke), gray, foliated, friable to massive, medium grained, with } 15 \\
\text { percent quartz, } 40 \text { percent feldspar, and white mica. }\end{array}$ \\
\hline 05JEA184A & 64.0405 & -148.5271 & 425415 & 7102228 & 06W & $\begin{array}{l}\text { Schist; (meta-graywacke), gray, foliated to massive, medium to coarse grained, with } \\
45 \text { percent quartz }+ \text { feldspar crystals }(2 \mathrm{~mm}) \text {, chlorite, and white mica. }\end{array}$ \\
\hline 05LF6A & 64.0481 & -148.8604 & 409168 & 7103504 & 06W & $\begin{array}{l}\text { Metarhyolite: (metagranite), brown, blocky, foliated, hornfelsed, fine to medium } \\
\text { grained, meta felsic rock, with } 15 \text { percent quartz eyes (1-2 mm), } 20 \text { percent relict } \\
\text { feldspar ( } 1 \mathrm{~mm}) \text {, in a brown splotchy matrix. Industry map unit of "Dacite crystal } \\
\text { tuff'. }\end{array}$ \\
\hline 05LF19A & 64.0391 & -148.8644 & 408940 & 7102511 & 06W & $\begin{array}{l}\text { Semi-schist; (meta-graywacke), foliated, fine grained, with } 15 \text { percent quartz eyes, } \\
20 \text { percent feldspar grains }(2 \mathrm{~mm}), 25 \text { percent biotite, in a } 70 \text { percent fine granular } \\
\text { quartz-feldspar matrix. }\end{array}$ \\
\hline 05LF21A & 64.0350 & -148.8561 & 409333 & 7102036 & 06W & $\begin{array}{l}\text { Granite porphyry; (granite), } 20 \text { percent euhedral quartz, } 20 \text { percent white feldspar } \\
\text { phenocryst, in a sugary fine grained groundmass. } 5 \text { percent pits of altered mafics } \\
\text { (biotite?). }\end{array}$ \\
\hline 05LF41B & 64.0558 & -148.7405 & 415042 & 7104201 & 06W & $\begin{array}{l}\text { Semi-schist; (meta-graywacke), pale green, foliated, medium grained, with } 30 \\
\text { percent relict quartz (1-3 mm), } 50 \text { percent relict feldspar }(1-2 \mathrm{~mm}), 10 \text { percent } \\
\text { chlorite partings, and } 10 \text { percent other granulated crystals. }\end{array}$ \\
\hline 05LF54A & 64.0669 & -148.6373 & 420112 & 7105296 & 06W & $\begin{array}{l}\text { Schist; (meta-graywacke), foliated, medium grained, porphyroclastic, with } 15 \text { percent } \\
\text { quartz eyes }(1-2 \mathrm{~mm}), 30 \text { percent feldspar eyes }(1-2 \mathrm{~mm}), 30 \text { percent chlorite, and } \\
25 \text { percent interfoliated fine grained quartz + feldspar. }\end{array}$ \\
\hline 05LF65A & 64.0679 & -148.5960 & 422129 & 7105359 & 06W & $\begin{array}{l}\text { Semi-schist; (meta-graywacke), foliated, medium grained porphyroclastic, with } 10 \\
\text { percent quartz eyes, } 40 \text { percent feldspar eyes, } 20 \text { percent chlorite, and } 30 \text { percent } \\
\text { fine grained feldspar + quartz. }\end{array}$ \\
\hline 05LF138A & 64.0517 & -148.5013 & 426708 & 7103442 & 06W & $\begin{array}{l}\text { Schist; (meta-graywacke), foliated, fine grained, porphyroclastic, with } 5 \text { percent } \\
\text { quartz eyes }(1 \mathrm{~mm}), 20 \text { percent feldspar eyes }(1-2 \mathrm{~mm}), 20 \text { percent fine grained } \\
\text { quartz-feldspar lenses, and } 55 \text { percent dark green-brown chlorite. }\end{array}$ \\
\hline
\end{tabular}




\begin{tabular}{|c|c|c|c|c|c|c|}
\hline Sample Number & Latitude & Longitude & UTM E & UTM N & Zone & Description \\
\hline 05LF139A & 64.0548 & -148.5043 & 426569 & 7103791 & 06W & $\begin{array}{l}\text { Schist; (meta-graywacke), mega-porphyroclastic, foliated, very coarse grained, with } \\
5-30 \text { percent feldspar augens }(1-5 \mathrm{~cm}) 15-30 \text { percent chlorite lenses }(1-2 \mathrm{~cm}), 5 \\
\text { percent quartz }(1-3 \mathrm{~mm}), 15 \text { percent feldspar }(1-4 \mathrm{~mm}) \text {, in a greenish, very fine } \\
\text { grained chlorite-sericite, feldspar-quartz matrix. }\end{array}$ \\
\hline 05LF155A & 64.0978 & -148.5333 & 425269 & 7108616 & 06W & $\begin{array}{l}\text { Schist; (meta-graywacke), } 20-40 \text { percent feldspar }(1-3 \mathrm{~mm}), 1-10 \text { percent quartz } \\
\text { crystals, } 10-40 \text { percent feldspar-quartz bands, and foliated chlorite-white mica-brown } \\
\text { mica in streaky bands. Abundant chlorite-feldspar-calcite veinlets. }\end{array}$ \\
\hline 05LF230A & 64.0576 & -148.8429 & 410049 & 7104535 & 06W & $\begin{array}{l}\text { Skarn; (skarn), foliated, with acicular actinolite, cut by quartz-sericite veins, } 1 \text { percent } \\
\text { chalcopyrite, } 2 \text { percent pyrrhotite, trace arsenopyrite. Industry map unit "Mesozoic } \\
\text { meta-gabbro". }\end{array}$ \\
\hline 05LF231A & 64.0585 & -148.8577 & 409330 & 7104660 & 06W & $\begin{array}{l}\text { Skarn; (skarn), medium to coarse grained, random oriented actinolite with interstitial } \\
\text { plagioclase, 1-4 percent pyrrhotite, } 2-3 \text { percent chalcopyrite, } 1 \text { percent arsenopyrite. } \\
\text { Industry map unit "Mesozoic meta-gabbro". }\end{array}$ \\
\hline 05MBW24A & 64.0476 & -148.9128 & 406606 & 7103524 & 06W & $\begin{array}{l}\text { Rhyolite porphyry; (granite), tan to white to pale brown, weathered, with } 1 \text { percent } \\
\text { quartz phenocryst }(0.5-2.5 \mathrm{~mm}), 10 \text { percent feldspar phenocryst }(0.5-2.5 \mathrm{~mm}) \text {, in a } \\
\text { pale tan to white, aphanitic to faintly granular matrix. Intrusion is locally clay altered } \\
\text { and cut by quartz and brown tourmaline veins }(\leq 1 \mathrm{~cm} \text { wide). Quartz veins } \\
\text { associated with iron oxide cubes (pyrite?). }\end{array}$ \\
\hline 05MBW50A & 64.0475 & -148.9273 & 405897 & 7103538 & 06W & $\begin{array}{l}\text { Intermediate dike; (granodiorite), grayish green, brown weathering, not foliated, } \\
\text { porphyritic, with phenocryst of biotite and feldspar. Disseminated pyrite and } \\
\text { arsenopyrite ( } \leq 3 \text { percent) is spatially associated with biotite. }\end{array}$ \\
\hline 05MBW71A & 64.0427 & -148.9434 & 405095 & 7103019 & 06W & $\begin{array}{l}\text { Granodiorite; (tonalite), rusty weathering, equigranular, medium grained, with } 30 \\
\text { percent biotite and hornblende. }\end{array}$ \\
\hline 05MBW83A & 64.0672 & -148.9007 & 407262 & 7105687 & 06W & $\begin{array}{l}\text { Sandstone; spheroidally weathered or stream rounded boulders of gabbro ( } \pm \\
\text { diabasic texture), white quartz, black chert, granitic rocks, basalt, and } \\
\text { sedimentary rocks, coated with fine gravel. Sample analyzed was gabbro (mafic } \\
\text { dike) boulder. }\end{array}$ \\
\hline 05MBW201B & 64.0667 & -148.5533 & 424209 & 7105176 & 06W & $\begin{array}{l}\text { Alkali gabbro dike; (mafic dike), } 5 \text { feet wide, crosscuts foliation, brown, spheroidally } \\
\text { weathering, blocks of dark green, equigranular, fine grained, with } 33 \text { percent biotite, } \\
33 \text { percent plagioclase, and } 33 \text { percent clinopyroxene(?). }\end{array}$ \\
\hline 05MBW204A & 64.0682 & -148.5486 & 424440 & 7105339 & 06W & $\begin{array}{l}\text { Alkali gabbro dike; (mafic dike), brown weathering boulders ( } \leq 3 \text { inches), with } \\
\text { amygdules }(\leq 5 \mathrm{~mm}) \text { rimmed with pink feldspar/laumontite(?) and calcite. }\end{array}$ \\
\hline
\end{tabular}




\begin{tabular}{|c|c|c|c|c|c|c|}
\hline Sample Number & Latitude & Longitude & UTM E & UTM N & Zone & Description \\
\hline 05MBW218A & 64.0561 & -148.5772 & 423013 & 7104025 & 06W & $\begin{array}{l}\text { Alkali gabbro dike; (mafic dike), brown weathering, equigranular to faintly porphyritic, } \\
\text { fine grained, biotite bearing ( } 25 \text { percent), with } 5-8 \text { percent bright green epidote (or } \\
\text { olivine), and phenocryst of altered plagioclace }(\leq 1 \mathrm{~cm}) \text {. Probably contains } \\
\text { clinopyroxene and plagioclase. }\end{array}$ \\
\hline 05MBW418A & 64.0634 & -148.9766 & 403545 & 7105381 & 06W & $\begin{array}{l}\text { Pluton; (granite), equigranular, fine grained, with quartz veins } \pm \text { yellow and red } \\
\text { stains. }\end{array}$ \\
\hline 05RN215B & 64.0274 & -148.9289 & 405753 & 7101298 & 06W & $\begin{array}{l}\text { Granite dike or sill; (granodiorite) } 10 \mathrm{~m} \text { X } 50 \mathrm{~m} \text {, unaltered, slightly porphyritic, } \\
\text { medium grained. }\end{array}$ \\
\hline 05RN269A & 64.0000 & -148.5702 & 423202 & 7097762 & 06W & $\begin{array}{l}\text { Dacite; (dacite) medium green, massive, porphyritic, with } 10 \text { percent feldspar, } 10 \\
\text { percent biotite } \pm \text { hornblende, } 5 \text { percent quartz phenocryst }(2-4 \mathrm{~mm}) \text { in aphanitic } \\
\text { groundmass. }\end{array}$ \\
\hline 05RN270A & 64.0012 & -148.5669 & 423367 & 7097892 & 06W & $\begin{array}{l}\text { Andesite; (dacite), dark green, weathered, very fine to medium grained, with } 10 \\
\text { percent hornblende phenocryst, } 10 \text { percent feldspar phenocryst, in aphanitic } \\
\text { groundmass. }\end{array}$ \\
\hline 05RN277B & 64.0122 & -148.5540 & 424027 & 7099101 & 06W & Phyllite; (quartzite), black, graphitic, very fine grained. \\
\hline 05RN306A & 64.0152 & -148.5347 & 424980 & 7099416 & 06W & Phyllite; (quartzite), black, $2 \mathrm{~m}$ thick, very fine grained. \\
\hline 05RN311A & 64.0192 & -148.5442 & 424523 & 7099872 & 06W & $\begin{array}{l}\text { Granite gneiss; (arkosic meta-sandstone), coarse to fine grained, equigranular, with } \\
\text { feldspar > quartz, and no mafics. Feldspar altering to clay. }\end{array}$ \\
\hline 05RN312A & 64.0227 & -148.5503 & 424236 & 7100267 & 06W & $\begin{array}{l}\text { Semi-schist; (meta-granite), foliated, medium grained, with quartz, feldspar, sericite, } \\
\text { and distinctive pale green micas. }\end{array}$ \\
\hline 05RN313B & 64.0239 & -148.5509 & 424212 & 7100408 & 06W & $\begin{array}{l}\text { Phyllite; (meta-mafic, carbonate altered), medium green, very pale weathering, fine } \\
\text { grained, with chlorite and actinolite(?). }\end{array}$ \\
\hline 05RN321A & 64.0142 & -148.5093 & 426216 & 7099274 & 06W & $\begin{array}{l}\text { Greenstone; (meta-mafic), massive to strongly foliated, very fine grained, } \\
\text { metabasite, chlorite rich, and calcite in fractures. }\end{array}$ \\
\hline 05RN330A & 64.0148 & -148.5309 & 425164 & 7099363 & 06W & $\begin{array}{l}\text { Metabasite; (meta-mafic), medium green, massive, fine grained, with chlorite, } \\
\text { epidote, and calcite on fracture surfaces. }\end{array}$ \\
\hline 05RN330C & 64.0148 & -148.5309 & 425164 & 7099363 & 06W & Phyllite; (quartzite), black, calcareous, fine to very fine grained, with quartz eyes. \\
\hline 05RN331A & 64.0154 & -148.5328 & 425069 & 7099440 & 06W & Phyllite; (quartzite), black, $0.5-3 \mathrm{~cm}$ thick, quartz rich. \\
\hline 05RN332B & 64.0194 & -148.5341 & 425018 & 7099881 & 06W & Phyllite; pale yellow to green, aphanitic, finely laminated, and very fine grained \\
\hline 05R & 64.0475 & -148.8512 & 409613 & 7103426 & $06 \mathrm{~W}$ & $\begin{array}{l}\text { Phyllite; (meta-mafic, carbonate altered), very fine grained, with chlorite and no } \\
\text { carbonate Industrial map unit "Eva Creek phyllite". }\end{array}$ \\
\hline 05Z39A & 64.1260 & -148.7374 & 415408 & 7112013 & 06W & $\begin{array}{l}\text { Phyllite; (meta-rhyolite), green and white, with } 1-5 \mathrm{~cm} \text { long augens, in a finer grained } \\
\text { matrix of greenish gray, pale green, and white, sericite, chlorite, quartz, and feldspar. } \\
\text { Metavolcanic rock? }\end{array}$ \\
\hline
\end{tabular}




\begin{tabular}{|c|c|c|c|c|c|c|}
\hline Sample Number & Latitude & Longitude & UTM E & UTM N & Zone & Description \\
\hline 05Z85A & 64.0696 & -148.6603 & 418998 & 7105631 & 06W & $\begin{array}{l}\text { Granite porphyry; (granite) light gray, with } 15-20 \text { percent quartz phenocryst, with } \\
\text { possibly some amount of feldspar phenocryst, black elongated phenocryst of } \\
\text { hornblende? }(0.5-2 \mathrm{~mm}) \text {. }\end{array}$ \\
\hline $05 Z 102 A$ & 64.0829 & -148.6982 & 417190 & 7107162 & 06W & $\begin{array}{l}\text { Schist; (meta-graywacke), well foliated, fissile, with } 40 \text { percent porphyroclasts of } \\
\text { feldspar and quartz, and white mica. Metavolcanic? }\end{array}$ \\
\hline 05Z119A & 64.0577 & -148.6923 & 417400 & 7104342 & 06W & $\begin{array}{l}\text { Schist; (meta-graywacke), white to light gray, crenulated, porphyritic, with 5-7 } \\
\text { percent quartz porphyroblast, } 20 \text { percent }(1-2 \mathrm{~mm}) \text { punky-clay altered feldspar } \\
\text { porphyroblasts, and white mica. Metavolcanic? }\end{array}$ \\
\hline 05Z131A & 64.1237 & -148.8673 & 409078 & 7111939 & 06W & $\begin{array}{l}\text { Meta-granite porphyry; (meta-granite), schistose to semi-schistose, metagranite, with } \\
\text { augens up to } 6 \mathrm{~cm} \text { by } 2 \mathrm{~cm} \text {, quartz porphyroclasts }(0.5 \mathrm{~cm}), 25 \text { percent feldspar, and } \\
15 \text { percent quartz, in a pale green to green micaceous matrix. }\end{array}$ \\
\hline 05Z184A & 64.0725 & -148.9555 & 404608 & 7106360 & 06W & $\begin{array}{l}\text { Granite porphyry; (granite), light gray to pale yellow-orange, dark weathering, blocky, } \\
\text { unfoliated, with } 25 \text { percent angular to sub-rounded quartz phenocryst }(2-6 \mathrm{~mm}) \text {, in a } \\
\text { white aphanitic to sucratic matrix with light green white mica. }\end{array}$ \\
\hline 05Z204A & 64.0768 & -148.9811 & 403374 & 7106874 & 06W & $\begin{array}{l}\text { Schist; (meta-graywacke), green to greenish gray, mostly muscovite with up to } 10 \\
\text { percent lenticular quartz }(\leq 3 \mathrm{~mm}) \text { porphyroclasts. Metavolcanic rock. }\end{array}$ \\
\hline 05Z239A & 64.0735 & -148.7888 & 412739 & 7106230 & 06W & $\begin{array}{l}\text { Meta-granite; (meta-graywacke), gray with light brown, white, and light green } \\
\text { speckles of interlocking grains }(2 \mathrm{~mm}) \text {, foliated, plutonic textured, with } 15-20 \text { percent } \\
\text { quartz, } 60 \text { percent feldspar, } 20 \text { percent brown biotite to green chlorite. Trace } \\
\text { amounts of quartz and quartz-tourmaline veinlets and veins. }\end{array}$ \\
\hline
\end{tabular}


Table 4. Major-oxide, minor-oxide, and trace-element analyses for rocks collected in the Liberty Bell area of the Fairbanks A-4 Quadrangles, Alaska.

\begin{tabular}{|c|c|c|c|c|c|c|c|c|c|c|c|c|c|c|c|c|c|c|c|c|c|}
\hline e & $\mathrm{d}_{2} \mathrm{O}_{3}$ & $\mathrm{aOO}$ & $\mathrm{CaO}$ & $\mathrm{Cr}_{2} \mathrm{O}_{3}$ & $\mathrm{Fe}_{2} \mathrm{O}_{3}$ & $\mathrm{~K}_{2} \mathrm{O}$ & $\mathrm{MgO}$ & $\mathrm{MnO}$ & $\mathrm{Va}_{2} \mathrm{O}$ & $\mathrm{P}_{2} \mathrm{O}_{5}$ & $\mathrm{SiO}_{2}$ & $\mathrm{SrO}$ & $\mathrm{TiO}_{2}$ & LOI & Total & $\mathrm{Ba}$ & $\mathrm{Nb}$ & $\mathrm{Rb}$ & $\mathrm{Sr}$ & $\bar{Y}$ & $\overline{Z r}$ \\
\hline & $\%$ & $\%$ & $\%$ & $\%$ & $\%$ & $\%$ & $\%$ & $\%$ & $\%$ & $\%$ & $\%$ & $\%$ & $\%$ & $\%$ & $\%$ & ppm & ppm & ppm & ppm & ppm & ppm \\
\hline$\overline{A A}$ & 1.40 & 37 & 75 & 01 & $\overline{4.74}$ & 4.16 & .81 & .01 & .58 & .10 & $\overline{5.93}$ & $\overline{0.01}$ & 1.66 & 3.10 & $\overline{99.6}$ & 520 & 47 & 142 & $\overline{8}$ & $\overline{46}$ & 219 \\
\hline & 52 & 07 & 8.27 & 0.02 & 12.41 & 1.73 & 96 & 13 & 89 & 46 & 6.67 & .04 & .24 & 2.51 & 9.92 & 690 & 48 & 97 & 335 & 33 & 47 \\
\hline & 58 & 32 & 2.39 & .01 & .52 & 31 & 90 & .02 & .89 & .05 & 5.52 & .02 & .28 & 1.74 & 9.54 & 2860 & 129 & 106 & 19 & 52 & 718 \\
\hline $\mathrm{A}$ & 15 & 13 & 0.10 & 0.08 & .23 & .06 & 31 & 0.37 & .83 & .23 & 23.15 & 0.02 & 0.99 & 22.10 & 9.74 & 1250 & -5 & 36 & 45 & 12 & 63 \\
\hline & .57 & 31 & 35 & $<0.01$ & .72 & .88 & .45 & 0.01 & .63 & .02 & 1.73 & 0.02 & .11 & 4.03 & 9.82 & 1000 & 23 & 272 & 14 & 32 & 69 \\
\hline A & .53 & 15 & .08 & $<0.01$ & 3.07 & .70 & .90 & 0.02 & 1.87 & .14 & 71.02 & .01 & .40 & .98 & 99.87 & 1310 & 10 & 189 & 79 & 23 & 73 \\
\hline $2 \mathrm{~A}$ & .99 & 13 & 0.22 & 0.03 & 2.46 & 68 & 95 & .03 & 31 & 17 & 73.59 & .01 & .37 & .47 & 99.4 & 050 & & 137 & 50 & 19 & 32 \\
\hline $8 \mathrm{~A}$ & .66 & 11 & 1.41 & $<0.01$ & 2.30 & 3.85 & .60 & 0.01 & 3.90 & .08 & 71.53 & .08 & .32 & 1.00 & 9.87 & 040 & 4 & 236 & 621 & 6 & 09 \\
\hline $3 A$ & .07 & 17 & 0.11 & 0.01 & 3.38 & 5.65 & .54 & 0.03 & .96 & .11 & 67.59 & .01 & .51 & 2.85 & 9.99 & 1350 & 14 & 178 & 54 & 20 & 192 \\
\hline$A$ & .04 & 09 & .17 & 01 & 68 & 4.65 & 53 & .02 & 11 & .13 & 77.22 & 0.01 & .20 & .58 & 9.43 & 880 & 7 & 249 & 29 & 31 & 98 \\
\hline $5 A$ & .28 & 15 & 0.52 & .02 & .04 & 4.35 & 0.93 & .02 & 2.48 & .11 & 71.65 & 0.02 & 0.45 & .95 & 9.96 & 1210 & 12 & 167 & 108 & 17 & 186 \\
\hline $26 \mathrm{~A}$ & .47 & 15 & 0.24 & $<0.01$ & 2.60 & 4.94 & 1.14 & 0.01 & 2.43 & 16 & 70.98 & .01 & 0.44 & 1.68 & 9.25 & 190 & 1 & 175 & 71 & 21 & 65 \\
\hline $27 \mathrm{~A}$ & 2.22 & 11 & 0.02 & $<0.01$ & 1.20 & 7.82 & 0.25 & $<0.01$ & 0.33 & 0.03 & 76.50 & 0.01 & 0.19 & 1.05 & 9.73 & 1030 & 33 & 188 & 47 & 31 & 16 \\
\hline $30 \mathrm{~A}$ & 1.96 & .31 & 3.00 & $<0.01$ & 3.41 & 2.71 & 2.23 & 0.01 & 2.94 & 0.16 & 67.60 & 0.09 & 0.55 & 1.52 & 9.51 & 3060 & 10 & 131 & 627 & 19 & 54 \\
\hline $33 A$ & .90 & .18 & 0.01 & 0.01 & 1.44 & 6.61 & 0.42 & 0.01 & 0.29 & 0.04 & 75.69 & 0.01 & 0.35 & 1.55 & 9.51 & 1480 & 10 & 217 & 48 & 26 & 20 \\
\hline $7 \mathrm{~A}$ & 21 & .11 & 0.17 & $<0.01$ & 2.08 & 7.28 & 0.43 & 0.07 & 0.64 & 0.13 & 73.70 & 0.02 & 0.41 & 1.63 & 9.87 & 890 & 7 & 221 & 69 & 25 & 12 \\
\hline BB & 60 & .09 & 0.24 & $<0.01$ & 1.11 & 5.96 & 0.31 & 0.01 & 0.82 & 0.17 & 77.20 & 0.01 & 0.32 & 1.32 & 9.16 & 750 & 10 & 195 & 66 & 29 & 29 \\
\hline $5 A$ & .05 & 13 & 0.13 & 0.01 & 3.25 & .03 & .73 & 0.13 & 2.45 & .11 & 73.55 & 0.01 & 0.37 & L.82 & 99.78 & 1090 & 10 & 126 & 58 & 22 & 48 \\
\hline A & 11 & .09 & 0.22 & $<0.01$ & 2.04 & 4.45 & 0.93 & 0.01 & 1.65 & .14 & 74.61 & 0.01 & 0.30 & .91 & 9.47 & 740 & 1 & 136 & 56 & 30 & 106 \\
\hline $4 \mathrm{~A}$ & 72 & .15 & 0.05 & $<0.01$ & 1.33 & 4.44 & 1.71 & $<0.01$ & 0.82 & 0.01 & 77.21 & 0.02 & 0.28 & 2.02 & 9.75 & 1290 & 14 & 103 & 70 & 17 & 06 \\
\hline 4B & 68 & .13 & 0.05 & .02 & 19 & 5.33 & 0.90 & 0.02 & 0.89 & 0.13 & 74.58 & 0.02 & 0.49 & 2.31 & 9.73 & 1320 & 11 & 163 & 69 & 32 & 44 \\
\hline $7 \mathrm{~A}$ & 54 & 12 & 0.19 & $<0.01$ & 1.83 & 6.08 & 0.48 & 0.05 & 0.91 & 0.13 & 74.21 & 0.01 & 0.31 & 2.02 & 9.89 & 1010 & 9 & 223 & 41 & 26 & 125 \\
\hline & 13 & 20 & 14 & 02 & 3.97 & 4.75 & 1.54 & .03 & 2.27 & 0.11 & 67.76 & 0.01 & 0.50 & 2.51 & 99.94 & 1740 & 13 & 109 & 51 & 24 & 233 \\
\hline & 75 & 30 & 15 & .01 & 20 & .70 & 1.16 & 0.08 & 2.47 & 0.13 & 68.36 & .01 & 0.52 & 2.10 & 9.93 & 2500 & 14 & 100 & 54 & 23 & 35 \\
\hline & 54 & 0.18 & 0.22 & $<0.01$ & 24 & 91 & 1.10 & 0.02 & 2.74 & 0.17 & 69.09 & 0.01 & 0.56 & 2.27 & 100.05 & 1580 & 16 & 116 & 4 & 32 & 68 \\
\hline $9 \mathrm{~A}$ & .39 & 13 & 0.18 & 0.01 & 2.87 & 4.20 & 0.72 & 0.01 & 3.12 & 0.16 & 70.60 & 0.01 & 0.47 & 1.99 & 99.86 & 1210 & 4 & 93 & 61 & 28 & 21 \\
\hline $2 \mathrm{~A}$ & .75 & 0.18 & 0.11 & $<0.01$ & 4.59 & 5.08 & 1.77 & 0.09 & 2.84 & 0.12 & 64.76 & .01 & 0.61 & 2.55 & 9.46 & 1620 & 15 & 109 & 44 & 25 & 45 \\
\hline $1 \mathrm{~A}$ & 44 & 0.17 & 0.14 & 22 & 2.41 & 6.03 & 0.68 & 0.02 & 1.16 & .14 & 73.31 & 01 & 0.32 & 1.88 & 9.72 & 1580 & 1 & 186 & 9 & 26 & 41 \\
\hline & 70 & 0.17 & 0.01 & $<0.01$ & 1.35 & 7.83 & 0.09 & 22 & 0.20 & 03 & 73.73 & .01 & 0.43 & 1.51 & 9.08 & 1340 & 10 & 212 & 20 & 22 & 59 \\
\hline $74 \mathrm{~A}$ & 69 & 0.18 & 11 & & 3.19 & 3.65 & 1.32 & $<0.01$ & 3.38 & 0.09 & 70.33 & 01 & 0.51 & 1.93 & 99.41 & 1630 & 12 & 77 & 39 & 19 & 189 \\
\hline $33 \mathrm{~A}$ & 57 & 16 & 22 & $<0.01$ & 2.59 & .81 & 0.95 & 0.01 & 2.01 & 0.14 & 69.66 & .01 & 0.39 & 2.18 & 99.7 & 1340 & 10 & 153 & 62 & 22 & 157 \\
\hline $84 \mathrm{~A}$ & .71 & .14 & 36 & 01 & 3.38 & 5.66 & 1.20 & 0.06 & 1.40 & 0.11 & 70.07 & .01 & 0.40 & 2.64 & 100.15 & 1260 & 10 & 126 & 40 & 22 & 161 \\
\hline $5 \mathrm{LF} 6 \mathrm{~A}$ & 79 & 0.26 & 1.00 & $<0.01$ & 2.98 & .54 & 1.61 & .01 & 3.56 & .6 & 8.24 & 0.01 & 0.34 & 1.44 & 99.83 & 2260 & 99 & 102 & 70 & 47 & 92 \\
\hline 5 5LF19A & 15.23 & 0.21 & 1.67 & $<0.01$ & 2.33 & 3.66 & 2.22 & $<0.01$ & $.2 \varepsilon$ & 0.04 & 69.39 & 0.02 & 0.26 & 2.03 & 99.34 & 1710 & 153 & 123 & 99 & 79 & 919 \\
\hline
\end{tabular}


Table 4. (continued)

\begin{tabular}{|c|c|c|c|c|c|c|c|c|c|c|c|c|c|c|c|c|c|c|c|c|c|}
\hline Sample & $\mathrm{Al}_{2} \mathrm{O}_{3}$ & $\mathrm{BaO}$ & $\mathrm{CaO}$ & $\mathrm{Cr}_{2} \mathrm{O}_{3}$ & $\mathrm{Fe}_{2} \mathrm{O}_{3}$ & $\mathrm{~K}_{2} \mathrm{O}$ & $\mathrm{MgO}$ & $\mathrm{MnO}$ & $\mathrm{Na}_{2} \mathrm{O}$ & $\mathrm{P}_{2} \mathrm{O}_{5}$ & $\mathrm{SiO}_{2}$ & $\mathrm{SrO}$ & $\mathrm{TiO}_{2}$ & LOI & Total & $\mathrm{Ba}$ & $\mathrm{Nb}$ & $\mathrm{Rb}$ & $\mathrm{Sr}$ & $\mathrm{Y}$ & $\mathrm{Zr}$ \\
\hline & $\%$ & $\%$ & $\%$ & $\%$ & $\%$ & $\%$ & $\%$ & $\%$ & $\%$ & $\%$ & $\%$ & $\%$ & $\%$ & $\%$ & $\%$ & ppm & ppm & ppm & $\mathrm{ppm}$ & $\mathrm{ppm}$ & $\mathrm{ppm}$ \\
\hline LF21A & 15.00 & 0.19 & $\overline{0.08}$ & 0.01 & 0.96 & 4.42 & 0.23 & 0.01 & 2.85 & 0.02 & 4.17 & 0.02 & 0.11 & 1.80 & 9.88 & 1560 & 21 & 274 & 168 & 34 & 83 \\
\hline 05LF41B & 13.08 & .10 & 1.08 & $<0.01$ & 1.36 & 6.57 & 0.97 & 0.06 & 0.74 & 0.11 & 72.57 & 0.01 & 0.32 & 2.32 & 99.28 & 840 & 9 & 186 & 88 & 26 & 125 \\
\hline 05LF54A & 15.46 & .20 & 0.12 & 0.01 & 3.76 & 5.33 & 1.57 & 0.05 & 2.27 & 0.12 & 68.23 & 0.01 & 0.56 & 2.28 & 99.98 & 1800 & 13 & 107 & 39 & 25 & 221 \\
\hline 05LF65A & 15.08 & .17 & 0.14 & $<0.01$ & 3.86 & 5.08 & 1.19 & 0.12 & 2.67 & 0.12 & 68.76 & 0.01 & 0.56 & 2.18 & 99.94 & 1550 & 13 & 134 & 28 & 30 & 221 \\
\hline 05LF138A & 15.78 & .21 & 0.26 & $<0.01$ & 4.07 & 6.57 & 1.27 & 0.02 & 2.41 & 0.14 & 66.56 & 0.01 & 0.68 & 1.92 & 99.92 & 1820 & 15 & 127 & 83 & 27 & 251 \\
\hline 05LF139A & 13.29 & 0.08 & 0.23 & $<0.01$ & 2.92 & 5.99 & 0.58 & 0.04 & 0.76 & 0.16 & 73.44 & 0.01 & 0.27 & 2.13 & 99.9 & 720 & 10 & 211 & 36 & 32 & 129 \\
\hline 5LF155A & 14.11 & 0.13 & 0.28 & $<0.01$ & 3.49 & 3.09 & 1.02 & 0.01 & 4.49 & 0.12 & 70.72 & 0.02 & 0.41 & 1.28 & 99.17 & 1310 & 12 & 51 & 102 & 24 & 194 \\
\hline J5F230A & 8.93 & 0.06 & 6.18 & $<0.01$ & 10.13 & 4.17 & 15.90 & 0.16 & 0.48 & 0.08 & 50.77 & 0.01 & 0.46 & 2.49 & 9.81 & 550 & $<2$ & 1005 & 125 & 30 & 140 \\
\hline 05LF231A & 7.77 & 0.01 & 11.71 & 0.01 & 10.86 & 0.15 & 14.01 & 0.31 & 0.50 & 0.03 & 50.01 & 0.03 & 0.44 & 3.72 & 99.57 & 80 & 10 & 10 & 226 & 35 & 128 \\
\hline 05MBW24A & 11.80 & 0.09 & 0.06 & $<0.01$ & 0.57 & 6.87 & 0.01 & $<0.01$ & 1.55 & 0.02 & 77.89 & 0.01 & 0.12 & 0.43 & 99.41 & 780 & 30 & 191 & 48 & 20 & 115 \\
\hline V50A & 15.70 & 0.36 & 1.41 & 0.03 & 5.94 & 4.79 & 2.51 & 0.03 & 2.86 & 0.22 & 62.45 & 0.06 & 0.49 & 2.76 & 99.61 & 3330 & 3 & 382 & 416 & 18 & 149 \\
\hline 5MBW71A & 16.13 & 0.12 & 4.76 & 0.01 & 5.94 & 3.47 & 2.96 & 0.08 & 2.78 & 0.22 & 61.50 & 0.08 & 0.66 & 0.86 & 99.58 & 1180 & 12 & 181 & 617 & 19 & 182 \\
\hline N83A & 14.90 & 0.04 & 12.02 & .02 & 11.89 & 0.51 & 6.62 & .18 & 1.86 & 0.12 & 48.12 & 0.03 & 1.48 & 2.17 & 9.96 & 560 & 7 & 13 & 191 & 21 & 87 \\
\hline /201B & 12.72 & 0.13 & 6.94 & 06 & 97 & 3.61 & 7.02 & 0.13 & 2.34 & 0.29 & 51.65 & 0.07 & 0.53 & 8.36 & 9.81 & 1240 & 5 & 133 & 528 & 16 & 154 \\
\hline $204 \mathrm{~A}$ & 14.03 & 13 & 93 & 55 & 34 & 2.59 & 6.98 & 0.11 & 2.83 & 0.17 & 53.34 & 0.08 & 0.65 & 6.35 & 9.89 & 1220 & 7 & 84 & 68 & 15 & 46 \\
\hline $218 \mathrm{~A}$ & .67 & .20 & 19 & 0.10 & 36 & 4.02 & 9.58 & 0.17 & 1.43 & 0.29 & 49.14 & 0.06 & 0.72 & 5.00 & 99.94 & 1930 & 4 & 144 & 505 & 21 & 122 \\
\hline 418A & 3.17 & 0.03 & 09 & 0.03 & 76 & 0.08 & $<0.01$ & 0.0 & 7.19 & 0.03 & 77.08 & 0.01 & 0.23 & 1.34 & 100.05 & 120 & 5 & 2 & 45 & 16 & 503 \\
\hline 15B & 15.44 & 0.57 & 2.46 & 02 & 4.29 & 3.77 & 2.89 & 0.03 & 2.58 & 0.21 & 64.54 & 0.07 & 0.62 & 2.40 & 99.89 & 5290 & 11 & 212 & 509 & 11 & 148 \\
\hline $69 \mathrm{~A}$ & 15.34 & .09 & 3.16 & $<0.01$ & 3.84 & 2.73 & 2.00 & 0.07 & 2.90 & 0.18 & 64.77 & 0.02 & 0.49 & 4.36 & 9.95 & 720 & 8 & 96 & 158 & 25 & 153 \\
\hline $70 \mathrm{~A}$ & 15.71 & 09 & 3.43 & 0.02 & 97 & 2.72 & 1.73 & 0.05 & .99 & 0.19 & 65.01 & 0.03 & 0.53 & 3.41 & 9.88 & 770 & 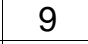 & 98 & 182 & 21 & 156 \\
\hline 77B & 16 & 28 & 09 & 01 & 33 & 1.73 & 0.37 & 0.01 & 0.17 & .14 & 84.91 & .01 & 0.34 & 2.93 & 9.46 & 2580 & 7 & 84 & 37 & 14 & 71 \\
\hline $06 \mathrm{~A}$ & .90 & 13 & 0.05 & 01 & 1.46 & 3.75 & 1.28 & 0.01 & 0.15 & .10 & 72.96 & 0.01 & 0.31 & 5.30 & 9.41 & 1180 & 12 & 130 & 10 & 20 & 119 \\
\hline $11 \mathrm{~A}$ & .50 & 0.04 & 0.02 & $<0.01$ & 1.14 & 3.85 & 0.50 & $<0.01$ & 0.13 & 0.03 & 81.74 & 0.01 & 0.12 & 1.82 & 9.89 & 270 & 9 & 262 & 9 & 19 & 67 \\
\hline 05RN312A & 13.04 & 0.11 & 0.02 & 0.02 & 1.50 & 4.84 & 0.27 & 0.01 & 0.13 & 0.05 & 77.48 & $<0.01$ & 0.25 & 1.84 & 99.57 & 910 & 8 & 214 & 16 & 33 & 122 \\
\hline 05RN313B & 16.37 & 0.08 & 0.40 & 0.04 & 9.80 & 2.32 & 5.40 & 0.11 & 2.44 & 0.43 & 54.50 & $<0.01$ & 2.97 & 4.70 & 99.56 & 820 & 35 & 65 & 34 & 52 & 256 \\
\hline 05RN321A & 15.90 & 0.09 & 5.42 & 0.04 & 10.19 & 1.41 & 7.51 & 0.12 & 4.05 & 0.25 & 47.90 & 0.02 & 1.48 & 5.29 & 99.69 & 900 & 20 & 35 & 145 & 30 & 260 \\
\hline 05R & 15.94 & 0.10 & 6.34 & 0.03 & 10.68 & 1.75 & 7.52 & 0.12 & 3.52 & 0.26 & 47.80 & 0.03 & 1.53 & 4.32 & 99.93 & 970 & 19 & 52 & 255 & 25 & 246 \\
\hline 05R & 9.89 & 0.08 & 0.07 & 0.01 & 0.93 & 3.13 & 0.81 & $<0.01$ & $<0.01$ & 0.02 & 82.00 & $<0.01$ & 0.38 & 2.26 & 99.57 & 750 & 13 & 98 & 11 & 15 & 47 \\
\hline $31 \mathrm{~A}$ & 3.47 & 0.13 & 0.08 & 0.03 & 0.58 & 1.17 & 0.47 & $<0.01$ & 0.12 & 0.01 & 84.66 & $<0.01$ & 0.15 & 7.55 & 98.39 & 1230 & 8 & 49 & 2 & 6 & 52 \\
\hline 05RN332B & 13.89 & 0.06 & 0.02 & $<0.01$ & 1.36 & 4.60 & 0.58 & $<0.01$ & 0.11 & 0.02 & 76.97 & $<0.01$ & 0.15 & 2.24 & 100 & 660 & 10 & 253 & 4 & 29 & 94 \\
\hline 05RN440A & 16.61 & 0.26 & 0.34 & 0.06 & 16.20 & 3.61 & 8.98 & 0.22 & 0.18 & 0.16 & 41.33 & $<0.01$ & 2.66 & 9.12 & 9.73 & 2480 & 30 & 202 & 26 & 23 & 158 \\
\hline 05Z39A & 13.28 & 0.12 & 0.23 & 0.02 & 1.96 & 5.86 & 0.67 & 0.01 & 1.37 & 0.16 & 74.33 & $<0.01$ & 0.32 & 1.48 & 9.83 & 1040 & 12 & 196 & 25 & 32 & 168 \\
\hline 05Z85A & 15.20 & 0.09 & 0.12 & $<0.01$ & 1.69 & 4.53 & 0.19 & 0.03 & 3.31 & 0.05 & 73.09 & 0.02 & 0.18 & 1.38 & 99.89 & 840 & 19 & 253 & 135 & 23 & 95 \\
\hline $5 \mathrm{ZZ102A}$ & 16.12 & 0.22 & 0.05 & $<0.01$ & 3.47 & 5.59 & 1.14 & 0.01 & 1.99 & 0.08 & 67.48 & 0.01 & 0.45 & 2.59 & 99.21 & 1840 & 12 & 146 & 66 & 33 & 216 \\
\hline
\end{tabular}




\begin{tabular}{|c|c|c|c|c|c|c|c|c|c|c|c|c|c|c|c|c|c|c|c|c|c|}
\hline mple & $\mathrm{Al}_{2} \mathrm{O}_{3}$ & BaO & $\mathrm{aO}$ & $\mathrm{Cr}_{2} \mathrm{O}_{3}$ & $\mathrm{Fe}_{2} \mathrm{O}_{3}$ & $\mathrm{~K}_{2} \mathrm{O}$ & $\mathrm{MaO}$ & $n c$ & $a_{2}($ & $\mathrm{P}_{2} \mathrm{O}_{5}$ & & $\mathrm{SrO}$ & & & \multicolumn{7}{|c|}{ ble 4.} \\
\hline & $\%$ & $\%$ & $\%$ & $\%$ & $\%$ & $\%$ & $\%$ & $\%$ & $\%$ & $\%$ & $\%$ & $\%$ & $\%$ & $\%$ & $\%$ & ppm & $\mathrm{ppm}$ & ppm & ppm & opm & ppm \\
\hline 05Z119A & 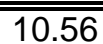 & 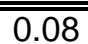 & "0.13 & 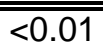 & 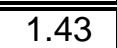 & 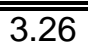 & 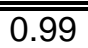 & 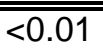 & "0.80 & 20.11 & $\overline{\mid \overline{79.48}}$ & "0.01 & 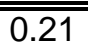 & 2.17 & 99.22 & "720 & $\overline{10}$ & 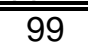 & $\overline{27}$ & $\overline{25}$ & 105 \\
\hline 05Z131A & 2.31 & 0.23 & 0.19 & $<0.01$ & 1.48 & 6.36 & 0.41 & 0.01 & 1.07 & 0.16 & 75.45 & 0.01 & 0.28 & 1.21 & 99.19 & 2010 & $a$ & 183 & 26 & 29 & 133 \\
\hline 05Z184A & 0.22 & 0.41 & 0.01 & 0.02 & 1.02 & 7.31 & 0.06 & $<0.01$ & 0.21 & 0.05 & 79.30 & 0.01 & 0.31 & 0.74 & 99.67 & 3350 & 7 & 232 & 24 & 16 & 123 \\
\hline 05Z204A & 16.26 & 0.19 & 0.13 & 0.01 & 4.24 & 4.95 & 0.57 & $<0.01$ & 0.19 & 0.10 & 68.64 & $<0.01$ & 0.50 & 3.63 & 99.42 & 1640 & 14 & 178 & 13 & 31 & 230 \\
\hline 05Z239A & 15.25 & 0.17 & 0.25 & 0.01 & 2.30 & 7.21 & 0.83 & 0.02 & 1.78 & 0.12 & 69.60 & 0.01 & 0.40 & 1.31 & 99.27 & 1470 & 9 & 239 & 53 & 20 & 154 \\
\hline
\end{tabular}


Table 5. Detection limits for geochemical analyses. Analytical methods include: FA-AAS = Fire Assay-Atomic Absorption Spectroscopy, FA-GRAV = Fire Assay-Gravimetric Finish, ICP-AES = Inductively Coupled Plasma-Atomic Emission Spectroscopy, AAS = Atomic Absorption Spectroscopy. NOTE: * possibly incomplete digestion dependent on mineralogy.

\begin{tabular}{|c|c|c|c|c|}
\hline Element & Units & $\begin{array}{l}\text { Lower } \\
\text { Detection } \\
\text { Limit }\end{array}$ & $\begin{array}{l}\text { Upper } \\
\text { Detection } \\
\text { Limit }\end{array}$ & $\begin{array}{c}\text { Analytical } \\
\text { Method }\end{array}$ \\
\hline $\mathrm{Au}$ & ppm & 0.005 & 10 & $\overline{F A-A A S}$ \\
\hline $\mathrm{Au}(+)$ & $\mathrm{ppm}$ & 0.05 & 1,000 & FA-GRAV \\
\hline $\mathrm{Ag}$ & $\mathrm{ppm}$ & 0.5 & 100 & ICP-AES \\
\hline $\mathrm{Al}$ & percent & 0.01 & 25 & ICP-AES \\
\hline As & $\mathrm{ppm}$ & 5 & 10,000 & ICP-AES \\
\hline $\mathrm{Ba}^{*}$ & ppm & 10 & 10,000 & ICP-AES \\
\hline $\mathrm{Be}$ & ppm & 0.5 & 1,000 & ICP-AES \\
\hline $\mathrm{Bi}$ & $\mathrm{ppm}$ & 2 & 10,000 & ICP-AES \\
\hline $\mathrm{Ca}$ & percent & 0.01 & 25 & ICP-AES \\
\hline $\mathrm{Cd}$ & $\mathrm{ppm}$ & 0.5 & 500 & ICP-AES \\
\hline Co & ppm & 1 & 10,000 & ICP-AES \\
\hline $\mathrm{Cr}^{\star}$ & ppm & 1 & 10,000 & ICP-AES \\
\hline $\mathrm{Cu}$ & ppm & 1 & 10,000 & ICP-AES \\
\hline $\mathrm{Fe}$ & percent & 0.01 & 25 & ICP-AES \\
\hline $\mathrm{Hg}$ & $\mathrm{ppm}$ & 0.01 & 100 & AAS \\
\hline $\mathrm{K}$ & percent & 0.01 & 10 & ICP-AES \\
\hline $\mathrm{Mg}$ & percent & 0.01 & 15 & ICP-AES \\
\hline $\mathrm{Mn}$ & ppm & 5 & 10,000 & ICP-AES \\
\hline Mo & ppm & 1 & 10,000 & ICP-AES \\
\hline $\mathrm{Na}$ & percent & 0.01 & 10 & ICP-AES \\
\hline $\mathrm{Ni}$ & $\mathrm{ppm}$ & 1 & 10,000 & ICP-AES \\
\hline$P$ & ppm & 10 & 10,000 & ICP-AES \\
\hline $\mathrm{Pb}$ & ppm & 2 & 10,000 & ICP-AES \\
\hline $\mathrm{S}$ & percent & 0.01 & 10 & ICP-AES \\
\hline $\mathrm{Sb}$ & ppm & 5 & 10,000 & ICP-AES \\
\hline $\mathrm{Sr}$ & ppm & 1 & 10,000 & ICP-AES \\
\hline $\mathrm{Ti}^{\star}$ & percent & 0.01 & 10 & ICP-AES \\
\hline $\bar{V}$ & ppm & 1 & 10,000 & ICP-AES \\
\hline$W^{*}$ & $\mathrm{ppm}$ & 10 & 10,000 & ICP-AES \\
\hline $\mathrm{Zn}$ & $\mathrm{ppm}$ & 2 & 10,000 & ICP-AES \\
\hline
\end{tabular}


Table 6. Detection limits for major-oxide, minor-oxide, and trace-element analyses. Analytical methods include: LBF-XRF = Lithium borate fusion and X-ray fluorescence spectroscopy, PP-XRF $=$ X-ray fluorescence spectroscopy on a pressed pellet. Note: $\mathrm{Fe} 2 \mathrm{O} 3=$ total iron as $\mathrm{Fe} 2 \mathrm{O} 3$; $\mathrm{LOI}^{*}=$ loss on ignition.

\begin{tabular}{|c|c|c|c|c|}
\hline & & \multicolumn{3}{|c|}{ ALS Chemex } \\
\cline { 3 - 5 } Element & Units & $\begin{array}{c}\text { Lower } \\
\text { Detection } \\
\text { Limit }\end{array}$ & $\begin{array}{c}\text { Upper } \\
\text { Detection } \\
\text { Limit }\end{array}$ & $\begin{array}{c}\text { Analytical } \\
\text { Method }\end{array}$ \\
\hline \hline $\mathrm{Al}_{2} \mathrm{O}_{3}$ & percent & 0.01 & 100.00 & LBF-XRF \\
\hline $\mathrm{BaO}$ & percent & 0.01 & 100.00 & LBF-XRF \\
\hline $\mathrm{CaO}$ & percent & 0.01 & 100.00 & LBF-XRF \\
\hline $\mathrm{Cr}_{2} \mathrm{O}_{3}$ & percent & 0.01 & 100.00 & LBF-XRF \\
\hline $\mathrm{Fe}_{2} \mathrm{O}_{3}$ & percent & 0.01 & 100.00 & LBF-XRF \\
\hline $\mathrm{K}_{2} \mathrm{O}$ & percent & 0.01 & 100.00 & LBF-XRF \\
\hline $\mathrm{MgO}$ & percent & 0.01 & 100.00 & LBF-XRF \\
\hline $\mathrm{MnO}$ & percent & 0.01 & 100.00 & LBF-XRF \\
\hline $\mathrm{Na}_{2} \mathrm{O}$ & percent & 0.01 & 100.00 & LBF-XRF \\
\hline $\mathrm{P}_{2} \mathrm{O}_{5}$ & percent & 0.01 & 100.00 & LBF-XRF \\
\hline $\mathrm{SiO}{ }_{2}$ & percent & 0.01 & 100.00 & LBF-XRF \\
\hline $\mathrm{SrO}$ & percent & 0.01 & 100.00 & LBF-XRF \\
\hline $\mathrm{TiO}{ }_{2}$ & percent & 0.01 & 100.00 & LBF-XRF \\
\hline $\mathrm{LOI}^{*}$ & percent & 0.01 & 100.00 & LBF-XRF \\
\hline $\mathrm{Total}$ & percent & - & - & Calculation \\
\hline $\mathrm{Ba}$ & ppm & 10 & 10,000 & PP-XRF \\
\hline $\mathrm{Nb}$ & ppm & 2 & 10,000 & PP-XRF \\
\hline $\mathrm{Rb}$ & ppm & 2 & 10,000 & PP-XRF \\
\hline $\mathrm{Sr}$ & ppm & 2 & 10,000 & PP-XRF \\
\hline $\mathrm{Y}$ & ppm & 2 & 10,000 & PP-XRF \\
\hline $\mathrm{Zr}$ & ppm & 2 & 10,000 & PP-XRF \\
\hline & & & & \\
\hline
\end{tabular}

